\title{
An Event Based Simulation to design a Rail Interchange Yard which provides Service to High Speed and Conventional Railways.
}

\begin{abstract}
Railway interchanges are key operational points on a railway. However, railways are changing due to rail networks being upgraded to include high speed lines. Therefore, to allow for the integration of high speed lines with current conventional railways there is a prevalent need for railway interchanges to be redesigned. The scope of this paper is to conduct a study to design a railway yard of the future, which will be able to facilitate an interchange between a high speed railway and a conventional railway. The design method implemented in this study is a progressive approach which is based upon a simulation with subsequent evaluations and revisions. The final designs given in this study have been proven through evaluation to be a promising stream of rail research. The designs have also allowed for a discussion to be carried out on the economic benefits which can be achieved for the United Kingdom's High Speed Two (HS2) project by utilising the railway interchanges designed in this study between the new high speed line and the current conventional rail network.
\end{abstract}

\section{Introduction}

The motivation of this work is based on that throughout history the railway has proven to be a key contributing factor to the growth rate of a country due to the economic benefits which it provides (Xuemei et al, 2008). In modern times, the positive contributing factor offered by railways can be seen to be increased by the introduction of a high speed railway (Department of Transport, 2012). However, high speed railways consequently present both new and increased challenges to the operations of a railway. These challenges are based upon data communication, tilt, speed control and human factors (Parsons Brinckerhoff, 2011). When a high speed train operates on a conventional track the train can exceed the maximum operational limits of the system presenting further challenges (BBC, 2013a). These challenges, which when not met and limits when exceeded, result in a tragedy such as the Santiago de Compostela derailment (BBC, 2013b). Therefore, it is integral for both maximum performance and safety that the system is controlled adequately.

The United Kingdom is currently one of the only remaining western countries which is not nationally connected by a high speed railway. However, this is set to change due to the passing of legislation which allows for a national high speed rail, HS2, to be built (HS2, 2014a). It is expected that the HS2 project will provide an economic benefit two times in magnitude of the cost which will be incurred to build it (HS2, 2014b). To achieve this economic benefit and for the railway to be successful, the operations of the railway must be carefully designed so that the system is optimised in terms of performance yet remains unequivocally safe.

The current plan for the HS2 Project is to purchase new rolling stock to run on the new system. Purchasing new rolling stock results in a large capital cost and as such it also does not utilise the maximum potential of the rolling stock which is available throughout the UK. The motivation of this work is to investigate what would have to be modified to allow conventional rolling stock to run on a high speed line, along with the time implication of these modifications. Through this 
investigation it will then become possible through the use of simulation software to design a railway interchange to accommodate an interchange between high speed and conventional railways, which will become increasingly more necessary in the future. Based upon the undertaken investigation and simulation it will then be possible to discuss the opportunity of delaying the purchase of dedicated high speed rolling stock for the HS2 project with the aim of achieving an economic saving.

The aim of this study is to design a railway interchange by means of a simulation to address the future commercial requirement of the railway industry for an interchange between a high speed railway and a conventional railway.

In order to develop a simulation model which is capable of fulfilling the needs of this study, it will be essential to advance current simulation methods which are utilised in train yard research. To achieve this advancement this study will draw on a number of different simulation design methods detailed and explained later in this paper which will be used synchronously to develop a new design method. The new developed method will then be able to be applicable to future rail research allowing for more complex models to be simulated.

There are a number of steps which have to first be complete to allow for the objective of this work to be achieved. The first step is to define what operating criteria a train should be capable of to be classified as high speed. The next step is to investigate the operational differences between high speed trains and conventional trains, which will allow for knowledge of what modifications are required to allow for a conventional train to run on a high speed track. Based on the results of this investigation it will be possible to implement the design methodology of this study. The design methodology of this study is a progressive design approach utilising a decomposition simulation method. The first step of this methodology is to form an initial simulation design based on the operations which are required in the interchange to modify rolling stock. From this initial simulation design a variable is altered based on an output with the aim of improving the design. For the purposes of this study the output is the queue length at an operational point in a yard and the variable is the quantity of track at each operational point. The result of this process is a final design of an interchange yard. This design then allows for an investigatory discussion based on whether, utilising current conventional rolling stock will allow for the purchasing strategy of rolling stock as part of the HS2 project to be altered and delayed with the aim of producing an economic saving.

The expected outcome is a simulation model which represents a promising design for an interchange yard between a high speed railway and a conventional railway. A visual representation of the methodological approach of this study (incl. simulation concepts and methods) can be seen in Diagram 1. 


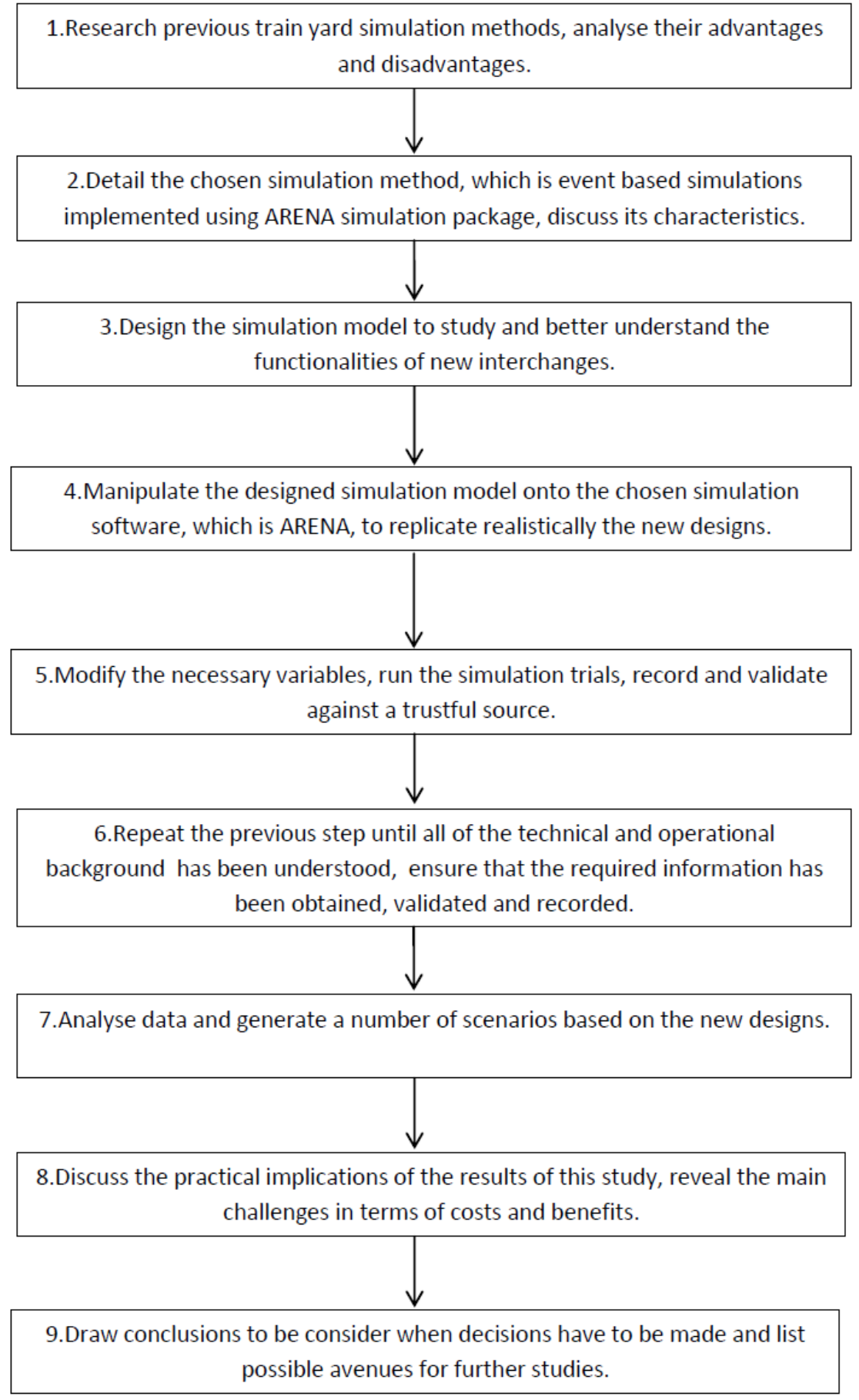

Diagram 1 - Flowchart of the methodological approach of this study.

As railways have become more prominent for both passenger and freight transport (Department for Transport, 2013) the most effective utilisation of railways has become significantly more important. The importance of running an effective railway is that it allows for more cost effective schedules and operational systems to be used. Simulating a system to trial a new operating system or modification can be considered to be strategic, operational, or tactical (Assad, 1980a). The evaluation of the effectiveness of modifications on a system is carried out scientifically through the use of computer simulations. These simulations are typically based upon real systems and data, and as such they can be used to evaluate the predicted effects on performance of modifications to a system to investigate whether they should be implemented (Marinov et al, 2009). 
A simulation is based upon two keys components, nodes and lines. Nodes represent processes carried out as part of the system, whilst lines represent the possible directional movement capabilities between nodes. The method of reducing a complex system into simplified processes represented by both nodes and lines is a modelling process termed decomposition (Marinov et al, 2009).

There is a wide range of simulation software available on the market which can be used, such as, Railsys, OpenTrack, SIMUL8 and Arena. The programming techniques which are used by each programme are different, although the user interface methods do have a similar scheme. Each programme works by having a system input block, which is based upon given parameters such as train arrival rates. The system input is then connected to blocks which are used to represent a process by routing arrows. The blocks which represent processes have parameters which are user defined and should be based upon investigated statistical data. Process blocks can either be an area where work is carried out, a server, or a storage area, a buffer (Shalliker et al, 1997). The final part of the user interface is a system output block which removes a train from the simulation. The final similarity is that reports are given which are specified by the user and show the output data of the simulation.

An important aspect when simulating a system is to use accurate parameters so that the overall simulation is accurate in replicating the real system (Flier, 2011). In yard simulations these parameters come from processing times such as for a brake inspection, and their respective queuing times. Due to this queuing nature typically analytical queuing modelling theory is implemented when simulating a complex rail yard. Whereby, the arrival process, to the process of leaving can be viewed as one queue broken down into subsequent smaller queues for each process under the decomposition modelling approach (2009). (Assad, 1980b) discusses a summation of different mathematical queuing methods such as exponential, Poisson and Erlang. Cooper (1981) builds upon this by providing a more detailed explanation of queuing theory. However, the optimum method for model accuracy is to use real-world statistical data as suggest by Flier (2011).

The specific area of rail research which this work is encompassed by is simulating yard operations. Previous work which has been carried out in this field is by Marinov et al (2009) which utilises the simulation software SIMUL8 to evaluate the optimum operations in a flat shunted freight yard utilising a decomposition method of simulating the process. Subsequent work which was carried out based upon the outcome of this work and which utilised a similar modelling method was Marinov et al (2011). Marinov et al (2011) was research which was carried out to ascertain the impact significant and insignificant deviation from a train schedule has on the lengths of queues in a yard.

In contrast to the decomposition method which was utilised by Marinov et al (2009), Zhou et al (2008) used a simulation design method which was based upon a classification as either a customer, a train, or a server, a process. Zhou et al (2008) utilised this customer and server simulation design method and Arena to investigate the optimum number of additional tracks for the Shanghai-South railway station servicing yard. The optimum number was that which provided the lowest through-put time whilst maintaining a high capacity. The key reason why a server and customer design methodology was utilised by Zhou et al (2008) is because the additional tracks are a theoretical design and it allows for this.

An alternate method to modelling a theoretical design is a progressive design model which was used by Williams (2011). A progressive design method is to first start with a basic concept and then to add additional features to the design to progress both the design and the results given by the system. Williams (2011) used a progressive approach to explain how to find the optimum areas in a system to place buffer zones to reduce bottlenecks. Since the work was to develop a final theoretical design from a base design a progressive approach was the most suitable for this.

The simulation design methodology which is implemented as the base methodology for this work is the progressive design approach utilised by Williams (2011). A progressive design methodology is the most suitable, as the aim of this work is a final theoretical design from a base 
design. However, this work will further the progressive design approach by incorporating the decomposition method which was used by Marinov et al (2009). Through the incorporation of the decomposition method into the progressive approach a more accurate simulation of the complex system is achieved. The programme which is used for this simulation is Arena. The methodology of this study also extends upon methodology previously implemented on Arena by Zhou et al (2008). The need for extending on the methodology of Zhou et al (Zhou et al, 2008) is that it does not accommodate for the design of such a complex system such as that being considered in this study.

By utilising the method described above it will allow the limitations on complexity of the modelling software ARENA to be overcome.

The paper organisation is shown in Diagram 2.

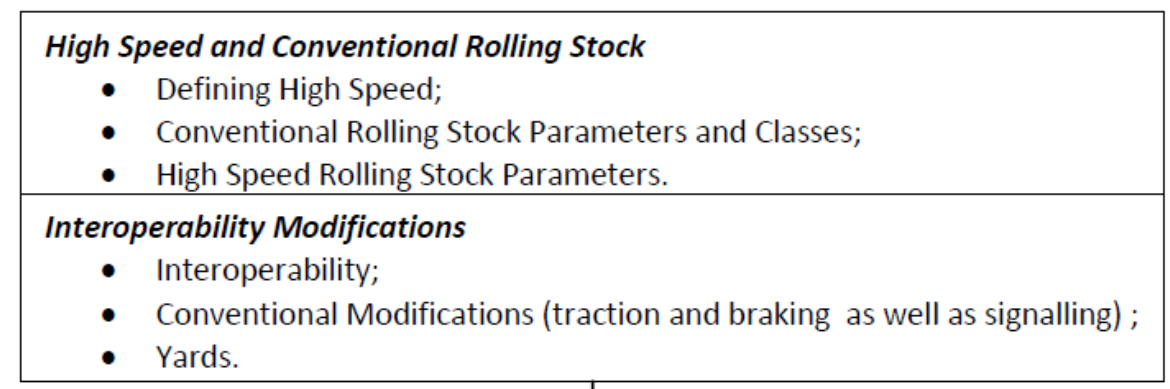

Simulation

- Technical Background;

- Simulation Design (General Inspection Module, Brake Inspection Modules, Locomotive Change Module, Arrival Module, Departure Module);

- Simulation Parameters (Number of Iterations, Simulation Duration, Warm-Up Time, Table of Parameters);

- Data Validation;

- Simulation Scenario Overview;

- Simulation Scenario One - Electrified Track to Electrified Track (Design, Method, Results);

- Simulation Scenario Two - Electrified Track to Non-electrified Track (Design, Method, Results).

\begin{tabular}{|l|}
\hline Practical Implications \\
\hline Conclusions and Further Research \\
\hline
\end{tabular}

Diagram 2 - Paper Organisation.

Specifically the remainder of this paper includes eight sections numbered 2 through to 7 . Section 2 is an investigation into the definition of a high speed train and the operational differences they possess compared to conventional trains. Section 2 also includes the types of conventional train which will be analysed in this paper. The next section, Section 3, is a discussion based on interoperability and subsequently what operations must be carried out in a yard to allow for a conventional train to travel between high speed and conventional tracks. Section 3 also considers what a railway yard is used for and how it is typically designed. Section 4 contains the simulation parameters used in this study and the validation of these parameters. Section 4 also contains the simulation and designs of an interchange yard based on two possible operational situations, along with the simulated implications on queuing times of trains at operational processing points in these 
interchanges. The next section, section 5 will consider the practical implications of implementing an interchange yard by discussing the notion of delaying the purchasing strategy of HS2, by incorporating an interchange yard and utilising current conventional rolling stock with the aim of achieving an economic saving. Section 6, is comprised of a conclusive statement and suggestions for further research on the topic of simulating interchange yards. The final section, section 7, is a list of all of the references which have been used in this study.

\section{High Speed and Conventional Rolling Stock}

\subsection{Defining High Speed}

To be able to discuss high speed rail effectively, first the specification of what constitutes a railway to be classified as high speed must be defined. An issue becomes apparent when trying to find a consensus on what operating parameters are required for such a classification to be given to a railway. Globally there are no similarities between the definitions which are offered by different countries therefore, a neutral consensus cannot be realised.

A key reason for the differing definitions stems from the capabilities of the various high speed systems across the world, and each nation wanting to be able to classify their railway as high speed at the time at which the railway was installed. The first railway to be classified as high speed was the Japanese Shikansen (Kable, 2007). The first train to operate on the Shikansen railway in 1964 reached speeds of up to $210 \mathrm{~km} / \mathrm{h}$. In comparison, due to advancements in technology in 2013 the maximum capability of the Shikansen railway is $320 \mathrm{~km} / \mathrm{h}$. Through a comparison of these values it can be seen that in a period of 49 years the capabilities of the Shikansen system have increased by $52 \%$. The impact of this advancement is that what was once considered high speed in Japan in 1964 could be inferred to not be high speed relative to the capabilities of the system in 2013. This inference supports the conclusion that high speed rail definitions are affected by and indeed relative to time.

Another key reason for the differing definitions can be found by comparing the definitions of a high speed railway from different countries. A congressional report compiled by the Department for Transport's Federal Railroad Administration on behalf of the American Congress, analysed the varying high speed rail definitions given in previous reports during the implementation of previous railways. The conclusion of the congressional report is that there are two classifications of high speed railway which can be given. The first classification is very high speed this is given to systems which have a speed of over $240 \mathrm{~km} / \mathrm{h}$ on tracks which are dedicated to high speed trains. The second classification is high speed, this is applicable to systems which are capable of a maximum speed between $144 \mathrm{~km} / \mathrm{h}$ and $240 \mathrm{~km} / \mathrm{h}$, on tracks which are not dedicated to high speed trains (Peterman et al, 2009).

The definition of high speed rail which is utilised by the constituent countries of the European Union is stated in European Directive 96/48/EC (European Union, 1996). The directive considers the railway system as a whole therefore, it gives parameters for both the infrastructure and rolling stock. There are two classifications which can be given, high speed and specially upgraded high speed. In the instance where a new high speed system is being implemented, the criteria which must be reached for this classification is that, the infrastructure must be capable of speeds in excess of $250 \mathrm{~km} / \mathrm{h}$, as should the rolling stock. If a conventional railway is upgraded, for it to meet the classification of high speed rail, the infrastructure must be adapted to meet the needs of planning constraints and topographical features. Another parameter for this classification is that the infrastructure and rolling stock must be capable of speeds in the region of $200 \mathrm{~km} / \mathrm{h}$. A further specification shared by both high 
speed rail and specially upgraded high speed rail is that the infrastructure and the rolling stock must have excellent characteristics of compatibility (European Union, 1996).

Similarly the definition of high speed rail which is used by the International Union of Railways (UIC) is adopted from that used by the European Union. (UIC, 2013a).

For the following work the definition of high speed rail which will be used is that which is used by the UIC (UIC, 2013a). As previously discussed, any definition which is used is a current definition that is effective for current technologies. Therefore, given a long enough period of time the definition will require a review, as the capabilities in terms of speed in the future will render the current definition ineffective.

\subsection{Conventional Rolling Stock Parameters and Classes}

It becomes important when investigating the ability of operating conventional stock on a high speed rail to first develop a set of operational characteristics for a sample of conventional and high speed rolling stock. The investigated operational characteristics can then be analysed to find the relative limit on capacity imposed by a conventional train on a high speed line. Investigating the operational characteristics of each type of rolling stock also provides a sample of conventional rolling stock which a simulation can be based upon.

In the United Kingdom there is a variety of conventional rolling stock, each with its own specific operating requirements. One main factor which causes the difference in the requirements of rolling stock is the method by which they are powered. The current methods of powering rolling stock in the UK are by either a Diesel-Electric bi-mode motor, a diesel motor or an electric motor, which draws power via third rail or pantograph (Rail.co.uk, 2013c).

The first rolling stock requirements and capabilities which will be discussed are from the British Class 66 which is a freight train. The British Class 66 is a bi-mode train, therefore, it is powered by a diesel engine and it is driven by an electric motor.. The track gauge requirement of the British Class 66 rolling stock is $1435 \mathrm{~mm}$ (standard gauge). The British Class 66 is capable of speeds of up to $65 \mathrm{mph}$ (4Rail.net, 2014).

Another bi-mode train with similar operating parameters, which is also used for the transportation of freight, is the British Class 70. Similar to the British Class 66, the British Class 70 rolling stock operates on track which is standard gauge. However, it has a slightly higher top speed of 75mph (Rail UK, 2013).

In contrast to the bi-mode class of trains the British Class 90 is only powered by overhead cables through a pantograph and driven by AC electric motors. The British Class 90 operates on standard gauge track. The top speed of this train is 110mph (Rail.co.uk, 2013a).

Another train which is powered in the same manner as the British Class 90 is the British Class 91. Similar to the British Class 90 the British Class 91 operates on track which is standard gauge. The British Class 91 is capable of a top speed of $140 \mathrm{mph}$. Although, a service speed of only $125 \mathrm{mph}$ is actually achieved (Rail.co.uk, 2013b). The reduction in top speed is because of limitations imposed by the maximum capabilities of the track (Network Rail, 2012b).

The current plan for the HS2 project is to have a 'phase one' high speed route between London and Birmingham (HS2, 2014c). The current conventional equivalent which covers this area is the West Coast Mainline (HS2, 2014d). A train which frequently operates on the West Coast Mainline is the British Class 390. The British Class 390 is a Pendolino train. A Pendolino is a type of train which tilts. The reason for this tilt is so that the train alters the centre of gravity when cornering to reduce the centripetal force which it experiences. This allows for the train to operate at a higher speed without the need for a straight high speed track (Kable, 2014d). The British Class 390 operates on 
track which is standard gauge. The maximum speed capability of this train is $140 \mathrm{mph}$. However, the top speed is limited to $125 \mathrm{mph}$ (Kable, 2014a).

The HS2 project is one which will not be complete for a number of years. Therefore, it becomes a necessity for the integrity and accuracy of the simulation that a train is included in the conventional train sample, which will be introduced to the UK rail network in the future and which will be operating on the network when the HS2 project is complete. The British Class 800 will be built by Hitachi and it is currently planned to be operating on the UK network by 2017. Similar to the British Class 66 and British Class 70 the British Class 800 is a bi-mode train. The operating parameters of the train are an expected service speed of $125 \mathrm{mph}$ with a maximum design speed of 140mph on standard gauge track (Hitachi, 2014b).

\begin{tabular}{|c|c|c|c|c|c|}
\hline $\begin{array}{c}\text { Rolling Stock } \\
\text { British Class }\end{array}$ & Freight/Transport & Drive Method & Gauge & $\begin{array}{c}\text { Top } \\
\text { Speed(mph) }\end{array}$ & $\begin{array}{c}\text { Operating } \\
\text { Speed(mph) }\end{array}$ \\
\hline 66 & Freight & Bi-mode & Standard & 65 & 65 \\
\hline 70 & Freight & Bi-mode & Standard & 75 & 75 \\
\hline 90 & Transport & Electric & Standard & 110 & 110 \\
\hline 91 & Transport & Electric & Standard & 140 & 125 \\
\hline 390 & Transport & Electric & Standard & 140 & 125 \\
\hline 800 & Transport & Bi-mode & Standard & 140 & 125 \\
\hline
\end{tabular}

Table 1 - Conventional rolling stock parameters (Rail UK, 2013; Rail.co.uk, 2013a; Rail.co.uk, 2013b; 4Rail.net, 2014; Hitachi, 2014b; Kable, 2014a).

Through a comparison of the speed capabilities of freight and transport rolling stock in table 1 , it is clear that rolling stock which is used for freight cannot achieve speeds close to that of a passenger transport train. The reason for this is that freight trains are more efficient in terms of operating costs if they carry a larger load at a slower speed than a smaller load at a higher speed (Network Rail, 2010). The impact this has when considering a conventional rail system is that it imposes a bottleneck on the capacity of the system.

Currently, the top speed of rolling stock, such as the British Class 390, is restricted by the capabilities of the track on which they operate (Network Rail, 2012b). This restriction can be seen in table 1 by the difference between the top speed and the operating speed. The logical inference which can be made from this is that, if a high speed train were to run on a conventional line a speed limitation would be imposed. In contrast to this, if a train, which has its speed limited by conventional track, were to run on a high speed track then it would no longer have such a limit imposed upon it, as the track design speed would be above the top speed of the rolling stock.

\subsection{High Speed Rolling Stock Parameters}

Currently, the only railway in the United Kingdom which meets the criteria set out by the UIC to be classified as a high speed railway (UIC, 2013a) is the HS1 line (Kable, 2014c). HS1 links London to the channel tunnel and therefore provides a link onwards to continental Europe (HS1, 2014). The high speed trains which are used on the HS1 line are assumed to be indicative of those which will be used on the HS2 line. Therefore, based upon this assumption, the capabilities of the rolling stock used on HS1 will be discussed to allow for a comparison with the specification on rolling stock set out in the HS2 technical report (HS2, 2009). 
The British Class 395 operates on the HS1 line. There are two ways in which the British Class 395 can draw power. The way in which the train is powered when operating on a high speed track is through a pantograph. In the United Kingdom overhead lines supply $25 \mathrm{KV}$ AC to a pantograph and subsequently to the electric induction motors, which allows for a top speed of $140 \mathrm{mph}$. The design operating gauge for the British Class 395 is standard gauge which allows for the train to operate on conventional lines making it a classical compatible train. When the British Class 395 is operating on rails which don't have an overhead line, it can draw power through a shoe making contact with a third rail. The voltage achieved through this method is $750 \mathrm{~V}$ DC which imposes a limit on the top speed, reducing it to 100mph (Hitachi, 2014a).

Another train which predominantly operates on the HS1 line is the British Class 373. The British Class 373 operates on British standard gauge and it is capable of a top speed of $190 \mathrm{mph}$. Similar to the British Class 395, the British Class 373 can be supplied with power by either overhead cables or a third rail.

Siemens are currently building and testing the British Class 374 which will be the next generation of rolling stock to operate on the HS1 line. The British Class 374 will operate on standard gauge at a speed of up to 200mph. A key focus in the design specification of the British Class 374 is that it will be fully interoperable (The Rail Engineer, 2013), this will further improve the rail connections between the United Kingdom and continental Europe.

The trains discussed thus far are however only used on the HS1 line. The nature of this report requires consideration to be made to the specification of future rolling stock and indeed reference trains which are considered in the HS2 technical specification as well as the assumption that they will be similar to those used on the HS1 line. The reference train which is considered for purposes of presenting theoretical figures in the HS2 technical specification (HS2, 2009) is the AGV, which is built by Alstom. The AGV is capable of speeds of up to 220mph on standard gauge (Alstom, 2014).

Plans for the HS2 project currently also involve the utilisation of rolling stock which is compatible with the current conventional network, these trains are termed 'classical-compatible'. A reference train is not given for this type. However, the specification does state that it must be fully compliant with all of the TSI (Technical Specification for Interoperability) standards for interoperability. The operating capability of the rolling stock will also be a minimum top speed of 220mph on standard gauge track (HS2, 2009).

\begin{tabular}{|c|c|c|c|c|c|}
\hline Rolling Stock & Railway & Drive Method & Gauge & $\begin{array}{c}\text { Top Speed } \\
(\mathrm{mph})\end{array}$ & Interoperable \\
\hline $\begin{array}{c}\text { British Class } \\
395\end{array}$ & HS1 & $\begin{array}{c}\text { Overhead/Third } \\
\text { Rail }\end{array}$ & Standard & 140 & Yes \\
\hline $\begin{array}{c}\text { British Class } \\
373\end{array}$ & HS1 & Overhead & Standard & 190 & No \\
\hline $\begin{array}{c}\text { British Class } \\
374\end{array}$ & HS1 & Overhead & Standard & 200 & Yes \\
\hline $\begin{array}{c}\text { Alstom AGV } \\
\text { (Proposed) }\end{array}$ & $\begin{array}{c}\text { Overhead } \\
\text { Classical- } \\
\text { Compatible }\end{array}$ & HS2 & Standard & 220 & Yes \\
\hline
\end{tabular}

Table 2 - High speed rolling stock parameters (HS2, 2009; The Rail Engineer, 2013; The Railway Centre, 2013; Alstom, 2014; Hitachi, 2014a). 
The key feature which can be found by comparing the top speed values of the rolling stock in table 2, is that, the top speed of the rolling stock proposed for the HS2 project is capable of a top speed which is greater than that of the rolling stock which is currently used on the HS1 railway. The reason for this is that the plans for the HS2 project are based upon the time which it would take to build the railway and the advances in technology which will occur in this time. Also, the infrastructure will be more adept to taking higher speeds than the HS1 railway due to advances in technology between their respective implementation dates (HS2, 2009; Kable, 2014c).

Another significant feature which can be noted from table 2 is that the more modern rolling stock is fully interoperable. The main benefit of this is that it will provide a level of future proofing to the technology of the new rolling stock which is proposed for the HS2 project. The reason for this is that the rail network in the United Kingdom is expected to be updated to meet the signalling needs of TSI (European Railway Agency, 2008). This will allow for full integration between the rail industry in the United Kingdom and continental Europe. Being more integrated will increase the degree to which the United Kingdom is connected to the rest of Europe and it will result in an economic benefit (Network Rail, 2012a).

Through a comparison of table 1 and table 2, it is clear that in terms of operating speed the maximum potential speed of conventional rolling stock, is $63 \%$ of the maximum potential of high speed rolling stock. The logical conclusion which this gives is that, as expected, the time taken for journeys on HS2 will be increased and the capacity reduced if only conventional rolling stock is used. However, the aim of this work is to consider a method which will allow for the purchasing strategy of HS2 to be altered and delayed, not to suggest that they are not needed. As such, the temporary limitations which conventional trains would impose on the system when being operated in juxtaposition with high speed trains are less significant due to the potential savings which will be generated. These savings are from spreading the cost of the high speed rolling stock over a longer period of time and also by increasing the utilisation of conventional rolling stock. To further investigate the commercial feasibility, the method of increasing the degree of interoperability between the two systems must be investigated and simulated.

\section{Interoperability Modifications}

\subsection{Interoperability}

An issue that developed as Europe became more interconnected across countries borders by rail networks was that rail networks differed from country to country in terms of both signalling and operations. This problem was realised in the UK when HS1 and the channel tunnel connected the UK to mainland Europe. To address the issue of interoperability the European Commission passed Directive 2008/57/EC. Directive 2008/57/EC ordered the European Railway Agency to publish a standard specification termed TSIs of which the constituent countries of Europe would have to adhere to which would result in an interconnected rail network without any operational differences. The Directive stated that there would be a TSI for; rolling stock, control command and signalling, operations and traffic management, infrastructure, energy and telematics (European Council, 2008).

Due to the passing of Directive 2008/57/EC the HS2 project must consequently adhere to the TSIs and their relevant sections. In terms of compatibility between current UK conventional trains and the HS2 line, if a conventional train is modified to meet essential operating TSI standards then it will be compatible with the HS2 line. 


\subsection{Conventional Modifications}

There are two main issues when considering modifying a conventional train so that it capable of operating on a high speed track. The first issue relates to the physical methods of traction and braking, the second issue relates to the communication interfaces between the rolling stock and the signalling system.

\subsubsection{Traction and Braking}

There are three main methods of providing tractive power to rolling stock, these are electric, diesel, and bi-mode. HS2 will be a railway which supplies power by overhead electric cables. Therefore, any locomotive which is running on it will need to draw power from the overhead line. This will clearly not prove an issue for an electric or bi-mode train. However, it would require a diesel locomotive carriage to be replaced by an electric locomotive carriage at an interchange yard.

Due to the higher speeds which rolling stock operates at on a high speed line it is also essential that a trains' brakes and braking system is inspected at an interchange. These inspections become more necessary if the rolling stock is older as there is a higher potential for the system to be damaged. It is also necessary if the locomotive carriage has been changed to ensure that the braking system has been connected correctly. A brake inspection other than that which is for regular maintenance becomes un-necessary for more modern trains as the train should be in an adequate state.

A general inspection will also need to be carried out at an interchange. A general inspection will be based upon checking the drive system and the remainder of the train. For freight, a general inspection is also extended to checking the cargo which is present on the train. In the case of modern trains a general inspection would need to only be a visual check as the train passes to ensure that it is passing through the yard in the correct direction and that it is seen to be operating correctly.

\subsubsection{Signalling}

The signalling method which will be used on the HS2 line is that which is required by the TSI for interoperability. The signalling communication method which is specified by the TSI is ERTMS (European Railway Traffic Management System). The basis of ERTMS is that there are three levels of sophistication at which a rail system can run, with each level being more autonomously connected than the last (Kable, 2014b).

The reason why it is important to consider signalling when attempting to incorporate the operation of conventional trains on a high speed system is that the system monitors the distance between trains and automatically signals for trains to brake if an issue occurs further up the line (Kable, 2014b). Therefore, if an issue occurred on a conventional train without ERTMS or further up the line from the train then this data would not be communicated, which results in the potential for an accident. This risk results in it becoming essential to upgrade a conventional train with an ERTMS system so that it can operate safely and efficiently on a high speed line.

The method of upgrading a conventional train with regard to the HS2 project is to install ERTMS level 2. ERTMS level 2 is necessary because it is in the project design specification for the infrastructure (Hunyadi 2011). The level 2 system works by introducing ATP (Automatic Train Protection) by means of GSM-R (Global System for Mobile Communications - Railways) communication between an antenna on a train and radio boxes called Eurobalise. Data from the train is sent to and analysed by a central signalling system which then sends a return signal which automatically controls the block movement of the rolling stock (SDL, 2014). 


\subsection{Yards}

The typical location at which operational activities are carried out on a train is at a train yard. The purpose of a train yard is to receive an incoming train and dis-assemble the necessary components, which may involve removing cars or functional components. The next stage of processing a train in a yard is to carry out any activities which will allow the train to complete its next journey without further work needing to be carried out (Bogsen et al, 2012). The train is then reassembled with the necessary cars and functional components which are required at, and on the journey to, the final destination.

Yards tend to be relatively large, the reason for this is that yards are mainly intended to sort freight cars onto the correct lines which will allow them to be taken to their next rail destination, as well as making sure the locomotive is able to complete its next journey. The typical method of sorting cars is by a hump design. A hump design is a method where cars are taken to the top of a hill by a shunt motor and then allowed to travel down the hill under the force of gravity at a controlled rate which is a function of both the loading of the car and the volume of traffic. The cars are then sorted at the bottom of the hill into their respective lines for the next stage of their journey (Bogsen et al, 2012).

The main process of a yard is to sort freight cars. However, when considering the aim of this work, which is to modify a conventional train so that it can be used to delay the purchasing of high speed specific trains, the main process of a yard in this context would not be for sorting but for modifying the rolling stock. Using the depot classification which is used in the UK by Network Rail the depot will be a Level 5 Maintenance depot capable of overhaul and rolling stock refurbishment (Parker et al, 2012). In the case of this work the yard would require the facilities of this level train depot as well as having functionality to move, sort, and store trains whilst modification work is undertaken on the locomotive. A number of modification processes can be carried out on the locomotives in the yard. These processes will be discussed in the simulation design stage of the following work.

It is suggested by Priemus et al (2004) that between $10-50 \%$ of the full journey time of a freight train is spent in a yard. However, due to the extent of work which may have to be carried out on trains during their respective modifications this percentage could be significantly higher. This would suggest that potentially the biggest improvement in the time efficiency of a train's journey when travelling through a modification yard would be from improvements in the design of yard. Based upon this, the design will be suggested, discussed and improved in the latter simulation sections of this work.

\section{Simulation}

\subsection{Technical Background}

To utilise the decomposition method of modelling a system, first the system must be defined explicitly so that it can be reduced into smaller components. To define the system first the process which must be undertaken in the yard must be described. The processes which occur are dependent on the type of train which is coming into the yard and whether the incoming and outgoing tracks are electrified. The case which requires the minimum number of processes is when an electrified, modern train arrives into the yard as it can essentially exit with only undergoing a passing inspection to ensure that it is operating correctly. The situation which is the most process intensive is when an older electric train has to interchange between an electrified high speed track and a non-electrified conventional track as this requires the locomotive to be changed, a general inspection of the train and then a brake inspection before it can be deemed to be safe to operate. Table 3 is a matrix which shows the classes of train analysed in this simulation with the processes which they require in a yard based upon the interchange type they require. The interchange type is dependent on whether the 
conventional rail they are travelling from or to is electrified or non-electric and as such both alternatives must be simulated.

\begin{tabular}{|c|c|c|c|c|c|c|}
\hline & \multicolumn{5}{|c|}{ Interchange Type } \\
\cline { 2 - 7 } & \multicolumn{2}{|c|}{ Electrified to Non-electrified } & \multicolumn{2}{c|}{ Electrified to Electrified } \\
\hline $\begin{array}{c}\text { Rolling } \\
\text { Stock }\end{array}$ & $\begin{array}{c}\text { General } \\
\text { Inspection }\end{array}$ & $\begin{array}{c}\text { Brake } \\
\text { Inspection }\end{array}$ & $\begin{array}{c}\text { Locomotive } \\
\text { Change }\end{array}$ & $\begin{array}{c}\text { General } \\
\text { Inspection }\end{array}$ & $\begin{array}{c}\text { Brake } \\
\text { Inspection }\end{array}$ & $\begin{array}{c}\text { Locomotive } \\
\text { Change }\end{array}$ \\
\hline $\begin{array}{c}\text { British } \\
\text { Class 66 }\end{array}$ & $\checkmark$ & $\checkmark$ & X & $\checkmark$ & $\checkmark$ & X \\
\hline $\begin{array}{c}\text { British } \\
\text { Class 70 }\end{array}$ & $\checkmark$ & $\checkmark$ & X & $\checkmark$ & $\checkmark$ & X \\
\hline $\begin{array}{c}\text { British } \\
\text { Class 90 }\end{array}$ & $\checkmark$ & $\checkmark$ & $\checkmark$ & $\checkmark$ & $\checkmark$ & X \\
\hline $\begin{array}{c}\text { British } \\
\text { Class 91 }\end{array}$ & $\checkmark$ & $\checkmark$ & $\checkmark$ & $\checkmark$ & $\checkmark$ & X \\
\hline $\begin{array}{c}\text { British } \\
\text { Class 390 }\end{array}$ & $\checkmark$ & $\checkmark$ & $\checkmark$ & $\checkmark$ & $X$ & X \\
\hline $\begin{array}{c}\text { British } \\
\text { Class 800 }\end{array}$ & $\checkmark$ & $\mathrm{X}$ & $\mathrm{X}$ & $\checkmark$ & $\mathrm{X}$ & $\mathrm{X}$ \\
\hline
\end{tabular}

Table 3 - A matrix of rolling stock and the processes they require in the yard depending on the interchange type.

On a base operational level, each process is similar for each type of train, the main difference is the duration of the process. For instance, a general inspection for a British Class 800 can be done by sight to ensure it is operating correctly and it is travelling through the yard in the correct manner. Whereas, a British Class 66 would require a more detailed visual inspection of the train components and also, since it is a freight train, the cargo. This would mean that the general inspection would be essentially the same however, due to the more detailed nature of the process, it would take longer for a British Class 66 than it would for a British Class 800. Extending this idea with queuing theory, both trains are in the same queue for the same processes and in fact are served by the same server. Therefore, the type of service is not different but the duration is. The change in duration of this service must be represented in the simulation. The method of specifying different processing times for each train type is simulated by having a dedicated process block for each train at each processing point to allow for different duration values to be set.

\subsection{Simulation Design}

Arena has been used in the absence of specific yard simulation software. Although this means that the simulation process has to be adapted by breaking each process down through decomposition. For the purposes of this study the decomposed processes are classified as simulation process modules. Modules have been constructed for the processes of general inspection, brake inspection, changing a train's locomotive, arrival of a train to the yard and the departure of a train from the yard. By representing these processes in this modular manner, they can be moved, copied and altered to fit in 
the necessary places in each simulation model without the need to re-create a different logic design each time. These modules are detailed and explained as follows;

\subsubsection{General Inspection Module}

The general inspection module is made from two main components, a decision logic block and a process block. The decision logic block is a tool which can be used in Arena to set a logical decision with a true or false answer based on a predesigned condition being matched against the input. In the case of the general inspection module the decision block is used to specify which routing arrow a train, or 'entity' as they are referred to in Arena, should follow. In Arena routing arrows are responsible for the directional movement of trains. After the decision block the routing arrow then takes the train towards the square boxes which are process blocks. Each train requires its own process block in this simulation. In reality this could be carried out in the same location by the same people however, this is the only

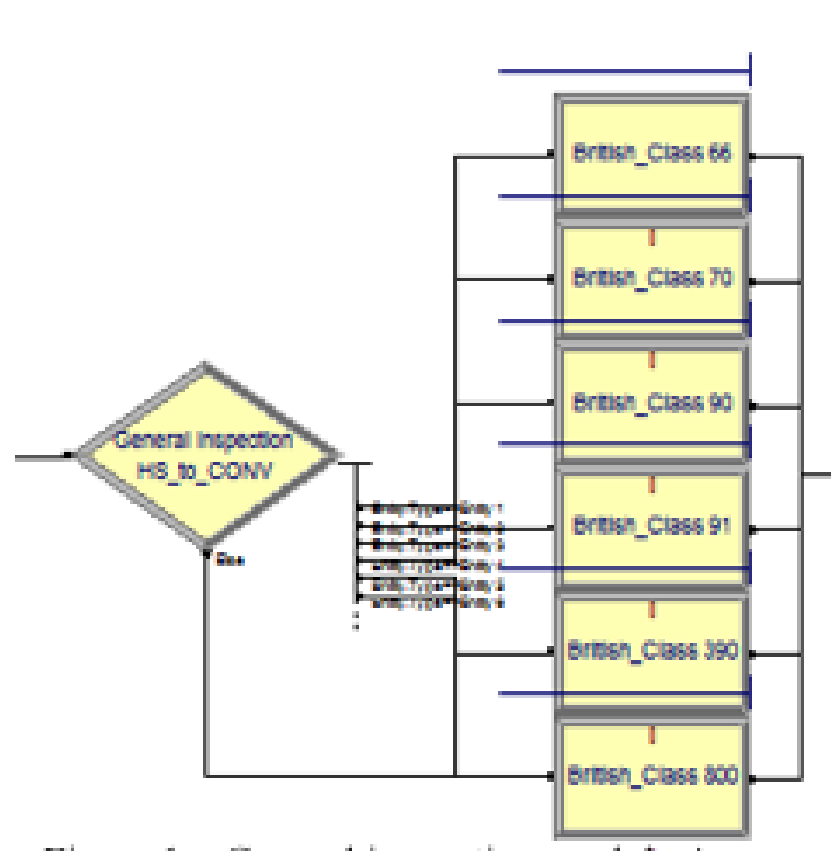

Figure 1 - General inspection module Arena way to vary the processing time for each train and its specific processing criteria. The process blocks are a 'seize delay release' type, which most accurately represents how a train would be dealt with in a yard at a processing station. The blue lines, which can be seen in figure 1 above each of the process blocks, are queues. These queues are a result of having a delay set in the process block.

\subsubsection{Brake Inspection Modules}

It can be seen by comparing figure 1 and figure 2 that the brake inspection module is set up in the same way in which the general inspection module is set up. Whereby, a train enters the decision block and it is routed towards the correct process block. The processing block then stops, holds, and delays the train for the given time before it is released which subsequently causes a queue. The main difference between the general inspection module and the brake inspection module is that some classes of trains do not require a brake inspection. In this instance the processing time can be set to zero and as such it has no effect on the progress of the train. The benefit of setting it up with a processing

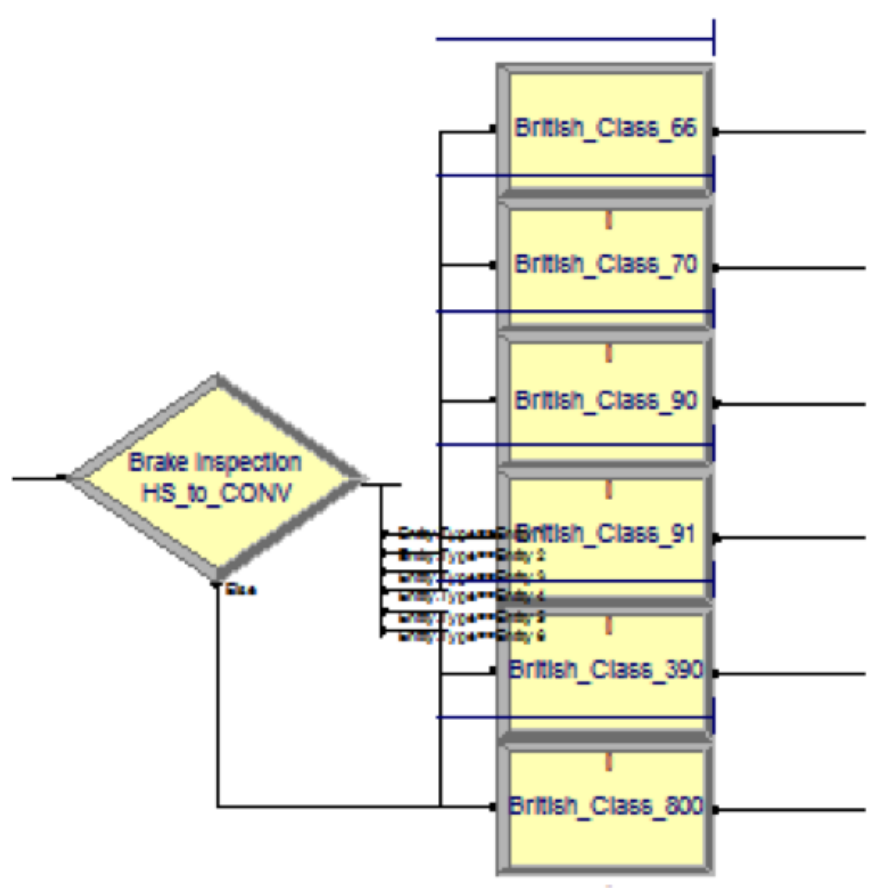

Figure 2 - Brake inspection module Arena diagram. 
block opposed to just routing it straight towards the next stage of the simulation is that data is still gathered on the frequency of trains which pass each block, which aids in interpreting the simulated results.

\subsubsection{Locomotive Change Module}

The module where a train's locomotive is changed is modelled in a similar way to the general inspection and brake inspection modules.

However, contrary to the logic which has been previously discussed in the brake inspection module section, in this module the rolling stock which do not require this process are directly rerouted towards the subsequent modules, as can be seen in figure 3 . The reason why this method is used here and not that which was used for the brake inspection module is because in a yard the area where a locomotive is changed would be separate from the rest of the yard. This is because it would have to have a large storage capacity as rolling stock would potentially have to wait for a significant amount of time for an alternative

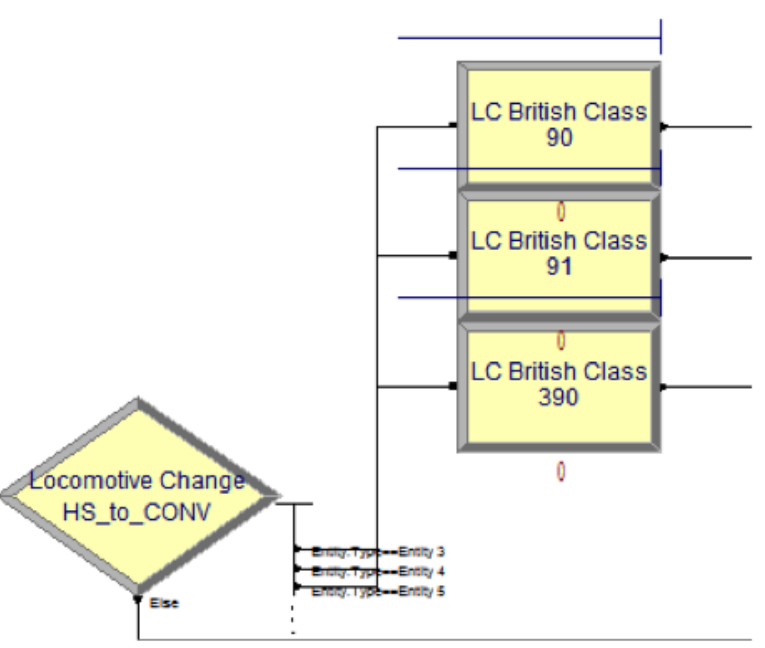

Figure 3 - Locomotive change module Arena diagram.

locomotive to become available. Therefore, by representing it separately in this way it is more indicative of the real situation making the simulation design more representative.

\subsubsection{Arrival Module}

Another important aspect in the simulation design is how the arrival process is designed. The difficulty when attempting to simulate the arrival process is firstly that the process is one which cannot be observed as the system does not currently exist. The difficulty is further extended as the specification for HS2 only states 18 high speed trains per hour (HS2, 2009). However, these are high speed trains and the aim of this work is to alter this by utilising conventional trains. The most difficult operating case will be taken to ensure the simulation has a higher level of integrity. Whereby, all of the trains are conventional trains and they arrive at a combined rate of 18 trains per hour with the intention of emulating the scenario. The arrival module for the simulation can be seen in figure 4 .

The blocks on the left hand side are 'create' blocks. Create blocks introduce a train to the system. The rate at which the block introduces trains can be selected from a number of methods. A probability distribution has been selected as the method of

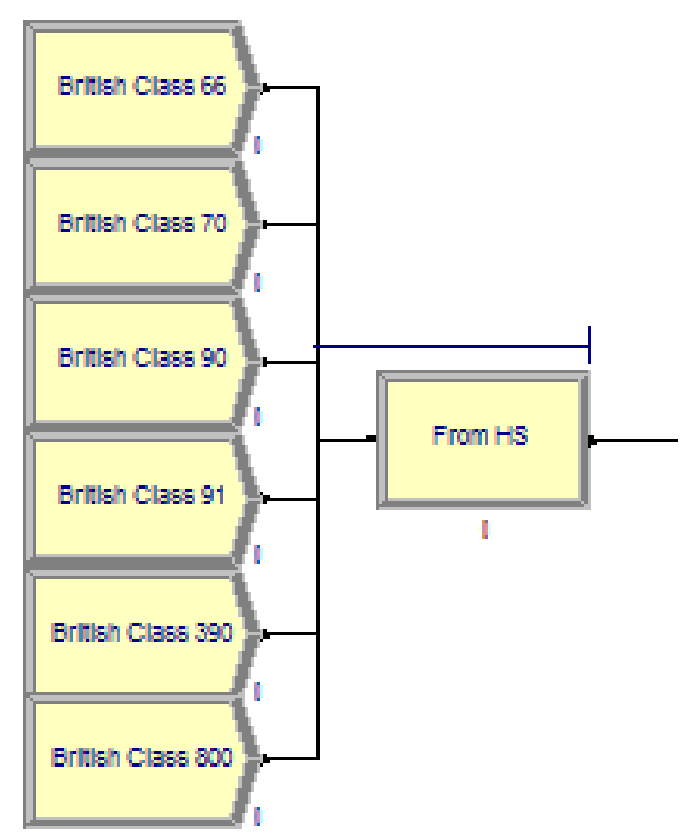

Figure 4 - Arrival process module Arena diagram. 
modelling the arrival rate of trains as it ensures that the train classes will arrive with a more random distribution. The distribution is set with a 'lambda' value so that the system emulates conventional trains arriving at the rate of 18 trains per hour. The create blocks are then directed towards a process block. The process block is used to limit the arrival rate to one train every 3.3 minutes. By limiting the arrival rate in this way it ensures that the trains are evenly spaced, as would be the case due to the ERTMS system which will be used on HS2 as it ensures equal train distribution to a set spacing of 18 trains arriving at a station per hour.

\subsubsection{Departure Module}

The final stage in a train yard is when a train departs the yard on to the required track. Analogous to this, the method by which a train then leaves the simulation is through a 'dispose' block which can be seen in figure 5 . The dispose block records the final data sets of each train which are the basis of the reporting

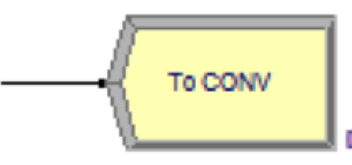

Figure 5 - Dispose block Arena diagram. function of Arena.

\subsection{Simulation Parameters}

The design of the process modules which are described in Section 6.2 are key to the integrity of the simulation. However, arguably more integral are the user input parameters. These are the parameters of which the interaction between the processes and the trains are based upon. As has been discussed at length in Section 5, the literature review of this work, the optimum parameters which can be used are those which are recorded from observing a real system. However, this work is based upon simulating a currently theoretical system, consequently it clearly cannot be observed. The method of gaining realistic parameters, which ensures the simulation has a higher degree of accuracy, is to use observed data from a current system with similar operations to the theoretical system.

The system and data used for the processing times of trains is taken from Marinov et al (2009). Although the data is not for each class of train which is used in this work due to different trains being used on that rail network it is indicative of similar types of trains and as such it can logically be applied to trains with similar operating capabilities.

The processing parameter values which have been used, have been set to be non-constant and to have a normal distribution within the range of results taken from Marinov et al (2009). The reason why the process block operating times have been set in this way is to simulate that of a real worker who would not finish each task with a constant time but rather it would be deviated around a mean time. This is one method of adding a slightly more random and realistic aspect to the simulation.

Another way in which a realistic aspect has been incorporated into the simulation is by adding a random variable with a defined range into the time taken for a locomotive to be changed. The process of changing a locomotive would involve changing between an electric powered locomotive and a diesel powered locomotive. The reason for changing the locomotive would be due to the track being electrified or requiring the rolling stock to be self-powered. The reason why a random variable with in a range has been used is because, although the actual time taken to change a locomotive would be deviated in the way described above for other processes, the wait time for the locomotive to become available would not be. The wait time would instead be based upon the disparity in time of both types of locomotive arriving and becoming available in the yard and a further influence on this would be any deviations from schedule. Therefore, due to this more random nature, a random variable with a defined range is the most representative simulation method. 
As previously discussed the arrival rate of trains which has been used in this study is taken from the HS2 project specification which proposes that 18 trains arrive per hour. However, this value is based on high speed stock (HS2, 2009). Therefore, to emulate this and to show the varied nature of conventional rolling stock which is available the 18 trains are comprised of a logical mixture of the rolling stock which have been selected as a sample for this study.

The parameters which are defined in the processing blocks are important for the way in which the simulated system interacts with trains, but equally significant to the simulation are the simulation parameters. The simulation parameters are user-defined and they have an effect on the simulation duration and accuracy. The specific parameters are, the number of iterations of the simulation which are carried out, the simulation running duration and the warm up time.

\subsubsection{Number of Iterations}

The number of iterations which are carried out are explicit to the accuracy of the results which are achieved. The reason for this is that more iterations provides more data points. The more data points there are the more accurate the average results therefore, more can be inferred from the results. However, after a number of iterations the results and average values will start to deviate less and so subsequent iterations are rendered unproductive. Also, the issue with having a larger number of iterations is that it uses more time of the simulation operator and it is also more intensive for the computer which is being used. Therefore, a balance must be achieved which is a function of accuracy, time and processing intensity. The value of 1000 is used in this work as it provides sufficient accuracy without taking too much time or being too intense on a computer's processor.

\subsubsection{Simulation Duration}

The simulation duration which is used is important as it must be sufficiently long to provide the performance characteristics and trends of the system. However, similar to the number of iterations, after a longer duration the data which is gathered may be considered unnecessary. Another way in which the simulation duration is critical is because the simulation is based on queues. The reason queues make the duration critical is that the queues are continuously accumulating. Therefore, a longer duration will show the extent to which the system is under or over serviced depending on the queue lengths. A simulation duration of 600 minutes has been used in this work based upon these factors.

\subsubsection{Warm-up Time}

An option when simulating on Arena is to specify a warm-up time. A warm-up time is a period of time Arena will run the simulation for before data is recorded. The benefit of using a warm up time is that it stops unrepresentative and uncharacteristic data which is often found when starting a system from an initial condition. The reason for this is that between an initial condition and that which is representative of a steady condition is a transient state. If data from a transient state was recorded it would be unrepresentative and anomalous as the scenario of going from no trains present in the yard to a constant maximum influx would not be a realistic one. To avoid data from a transient state being included, a warm-up time of 100 minutes has been used. 


\subsubsection{Table of Parameters}

\begin{tabular}{|c|c|}
\hline Parameter & Value \\
\hline Simulation Iterations & 1000 \\
\hline Simulation Duration & 600 (minutes) \\
\hline Warm-up Time & 100 (minutes) \\
\hline
\end{tabular}

Table 4 - Table of constant parameters.

\subsection{Data Validation}

There are two different data sets which are being utilised in this study. The first data set is the arrival rate of trains which was taken from the HS2 specification as the real system is not yet available to observe. The value which is given in the specification is 18 trains per hour (HS2, 2009). The mean value which was achieved in the simulation stage of this study was 18.6. This suggests an insignificant deviation from the original mean as it is within the $95^{\text {th }}$ percentile. The second data set used in this report is the processing times of trains which was taken from Marinov et al (2009). By utilising this data it meant that real world values could be used for the processing times of trains in the absence of the actual system to observe. The mean values which were calculated from the simulation are within the given data ranges.

\subsection{Simulation Scenario Overview}

The yard which is being simulated is used as an operational interchange to allow a conventional train to run from a high speed track to a conventional track. There are two potential scenarios which could occur depending on whether the conventional track is electrified. The first scenario which will be considered is when the yard is situated between a high speed track which is electrified and a conventional track which is also electrified. The alternative to scenario one is scenario two which is when the yard is situated between an electrified high speed track and a conventional track which is not electrified.

\subsection{Simulation Scenario One - Electrified Track to Electrified Track}

\subsubsection{Scenario One - Design}

The processing facilities which must be included in the yard to facilitate the first scenario are 'General Inspection' and 'Brake Inspection'. Therefore, the complete process for a train would be arrival to the yard, general inspection, brake inspection and then departure from a yard. This process is represented by Figure 6 .

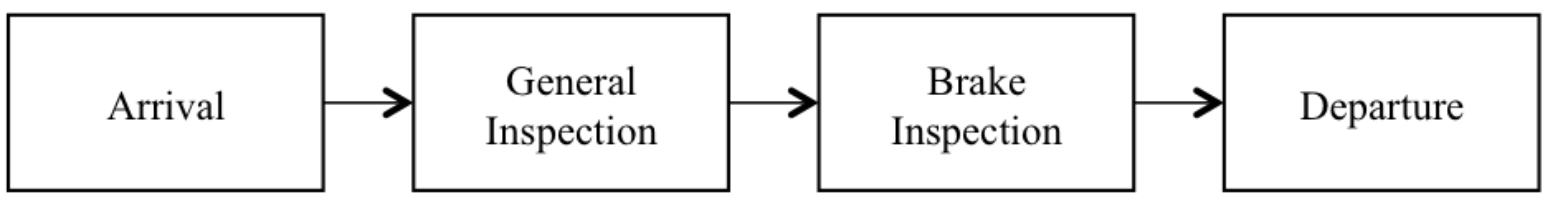

Figure 6 - Electrified high speed and electrified conventional process flow diagram.

The process flow diagram shown in figure 6 does not represent the full scale of the complexity of the problem. These additional complexities arise from different processing times for each type of train in the two operational processing stations. By utilising the modular design which has been previously discussed this additional complexity is reduced, as the modules have been 
designed to incorporate differing processing times. The method which has been used for allowing differing processing times is by having a different processing block in Arena for each train type of train at each processing station so that independent parameters can be set.

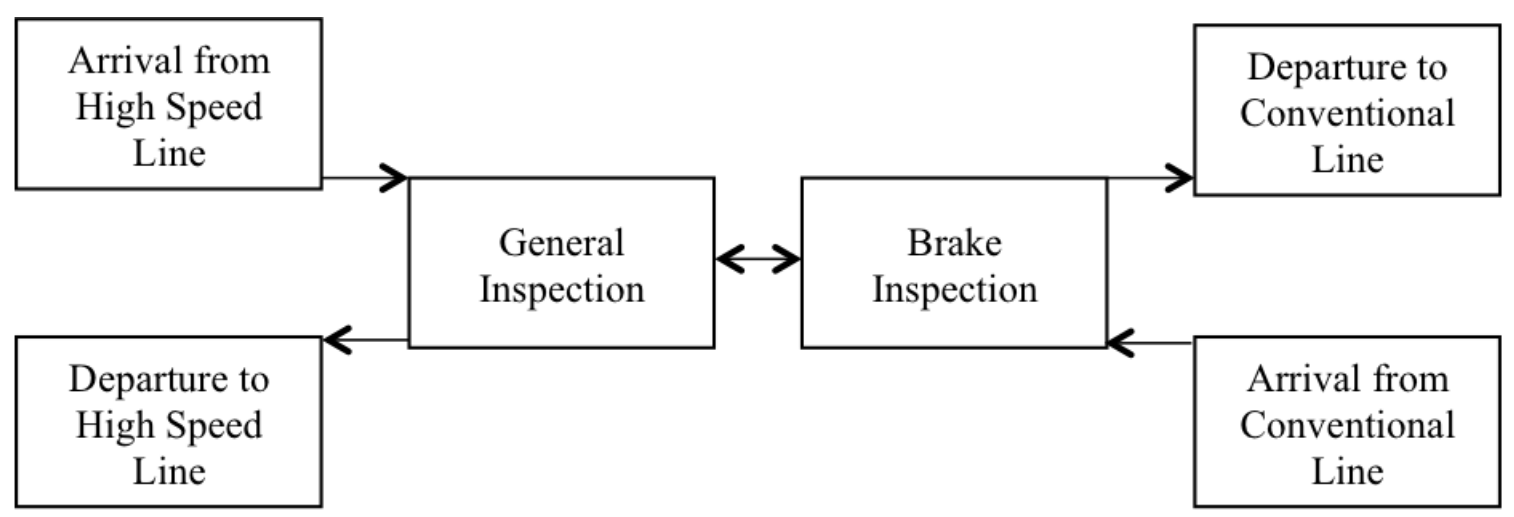

Figure 7 - Detailed electrified high speed and electrified conventional process flow diagram.

A further complexity which must be included in the simulation is that trains can arrive from either high speed or conventional lines. Therefore, the ability for trains to travel in both directions must be incorporated into the simulation. Figure 7 shows how this additional complexity affects the process flow of the system. However, Arena does not allow for multidirectional travel because blocks are linked using routing arrows which only facilitate movement in one direction. The method which has been implemented to simulate multidirectional travel is to have two separate processing channels which share their resources. Resources in Arena are what must be present at a processing block to allow for the process to be carried out, otherwise a queue develops. Sharing resources is analogous to workers working on multiple platforms, which means that trains must wait for the workers to become available to come to their platform to carry out work. Distributing a resource in such a way is termed a shared resource opposed to a non-shared resource which would be workers working at only one platform. To extend the method of shared resources to Arena to allow for a multidirectional system to be modelled first two separate process flow diagrams are constructed, one from a conventional line to a high speed line and the other from a high speed line to a conventional line. The processes which they pass through on their separate flow diagrams are input to have shared resources with the similar process block on the other process flow diagram. This is representative of the way which in reality regardless of direction, trains would be processed in the same area and not on a separate processing line. Figure 8 shows a process flow diagram with processes utilising shared resources.

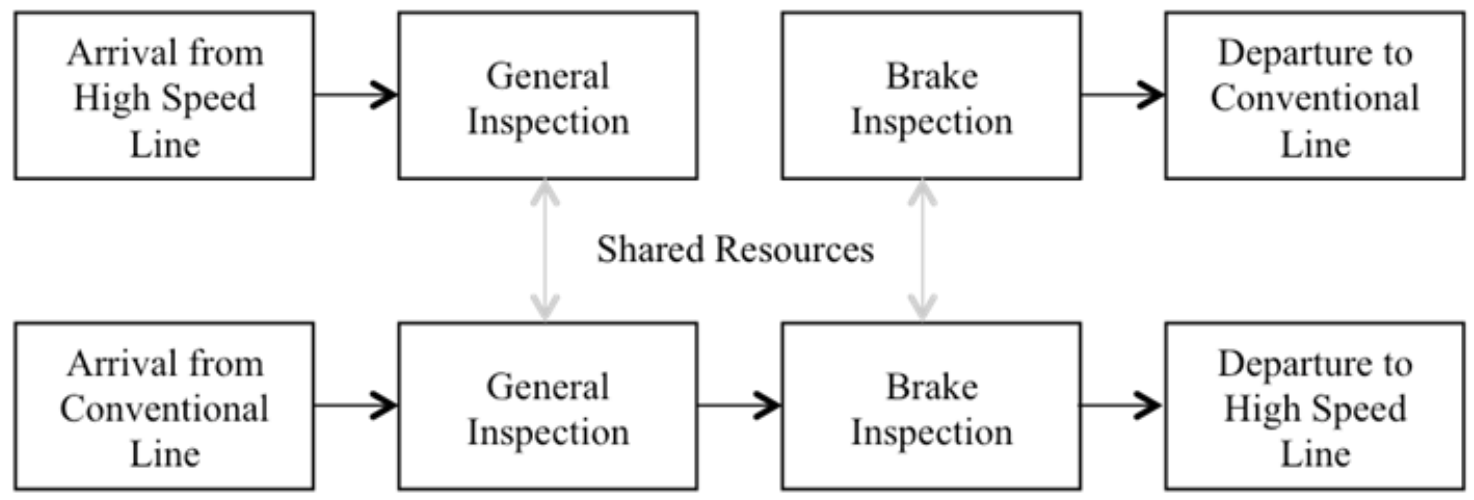

Figure 8 - Electrified high speed and electrified conventional process flow diagram with shared resources. 
Connecting the relevant modules based upon the process flow diagram in figure 8 leads to the formation of the Arena model which can be seen in Figure 9.
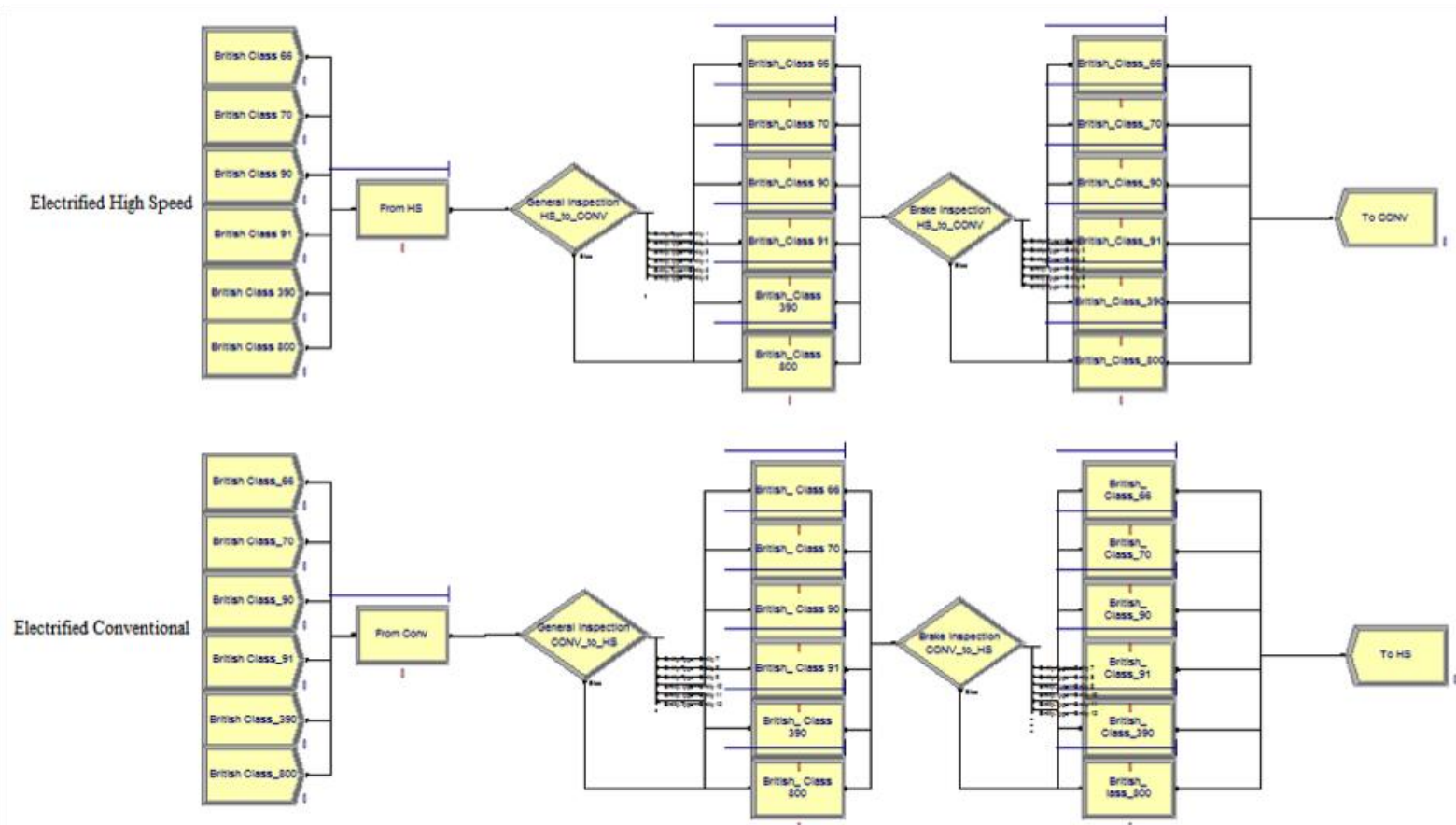

Figure 9 - Arena simulation of a yard between an electrified high speed line and electrified conventional line.

\subsubsection{Scenario One - Method}

The design methodology which is being carried out in this work, is a progressive design approach. Therefore, from the starting point of the initial simulation model it becomes important to have a basis for improving the theorised system. The method for improving the system will be to add more resources with the aim of reducing queue times. Therefore, given the constant parameters previously discussed the variable is the resources available and the output of the simulation is the queuing times.

The way in which resources will be assigned to the system is that similar classes of train will share resources. Therefore, the six trains involved in this simulation have been divided into three groups based upon their similarities, freight, traditional conventional trains and modern conventional trains, which can be seen in Table 5. The resources belonging to each group will be progressively increased so that the results on queue length can be observed.

\begin{tabular}{|l|l|}
\hline Group Name & Trains in Group \\
\hline Freight & British Class 66, British Class 70 \\
\hline Traditional Conventional & British Class 90, British Class 91 \\
\hline Modern Conventional & British Class 390, British Class 800 \\
\hline
\end{tabular}

Table 5 - Trains and the groups they will be classed by for the purposes of simulating scenario one

\subsubsection{Scenario One - Results}

Resource is the terminology used by Arena to allow the programme to be used for general purposes. In the case of the design of an interchange yard the term resource relates to the number of 
tracks present in each processing area. Initially with a low number of tracks the resultant queues were so large that the simulation could not be run to completion. Therefore, to find a meaningful initial point the number of tracks available had to be increased. From this new initial condition the number of tracks assigned to each category was continually increased with the resultant queuing times recorded. A large number of simulations were run, each with different quantities of track. However, the results which display the most important changes in queuing times are presented in Table 6 . The data in table 5 is the number of tracks given to each simulation group and the resulting simulated average queue lengths for each individual type of train at the given processing stations.

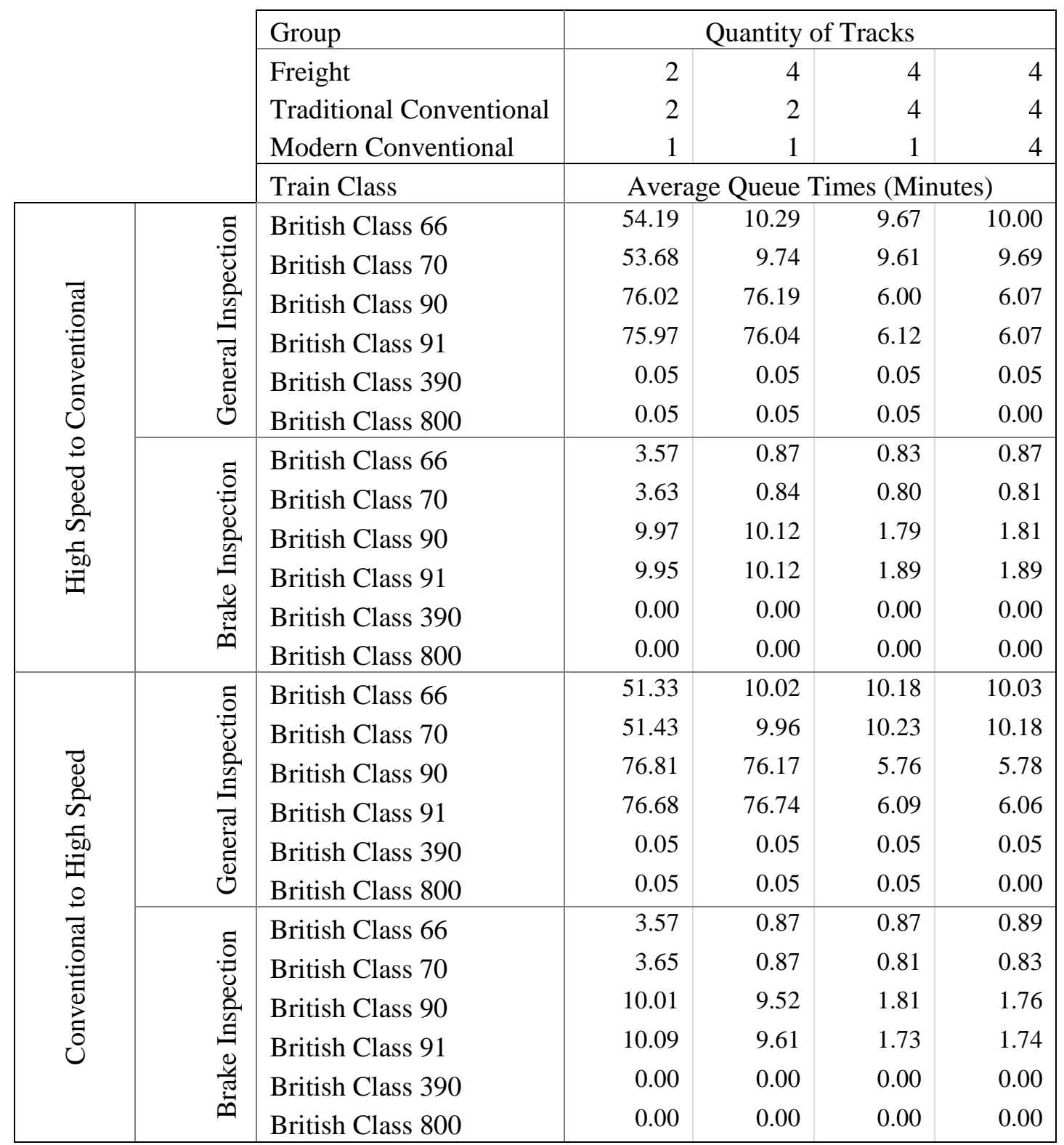

Table 6 - Electrified high speed to electrified conventional queuing data.

It can be seen in Table 6 that by using four tracks opposed to two tracks that the resultant queues for the freight, traditional conventional and modern conventional are reduced by approximately $80 \%, 95 \%$ and $0 \%$ respectively. The reason for these results is that by adding more tracks the work load per track is reduced which has the effect of alleviating the queue build up. However, this affect is not noted for the modern conventional group because when this group has a track independent of the other groups it is no longer bound to standard queues because the general 
inspection it requires is a visual inspection which can be done dynamically. Therefore, trains do not need to queue but instead they just need to slow down.

A further stipulation, which needs to be included in finding the quantities of track which will provide the most effective system is that, the utilisation of a track should not fall below $50 \%$. The value of 50\% has been chosen indicatively as below this value a system would be considered to not be feasible. A low efficiency and consequently an ineffective system is the reason simulations with track quantities for each process of five and above for traditional conventional and freight have not been included in the results. Therefore, based upon the criteria of balancing track utilisation with minimising queuing times, the track quantities which provide the most effective balance are four tracks for freight trains and four tracks for traditional conventional trains at both general inspection and brake inspection stations and one track for the general inspection of modern conventional trains.

The utilisation for these track quantities can be seen in Figure 10. However, the utilisation results for the track assigned to the modern conventional group have not been included as the simulated Arena utilisation quantity is incorrect. The reason the quantity is incorrect is due to the rolling stock in the modern conventional group being dynamic and not staying in the process block in Arena for long enough and so the utilisation is not comparable in the way it is for the other tracks.

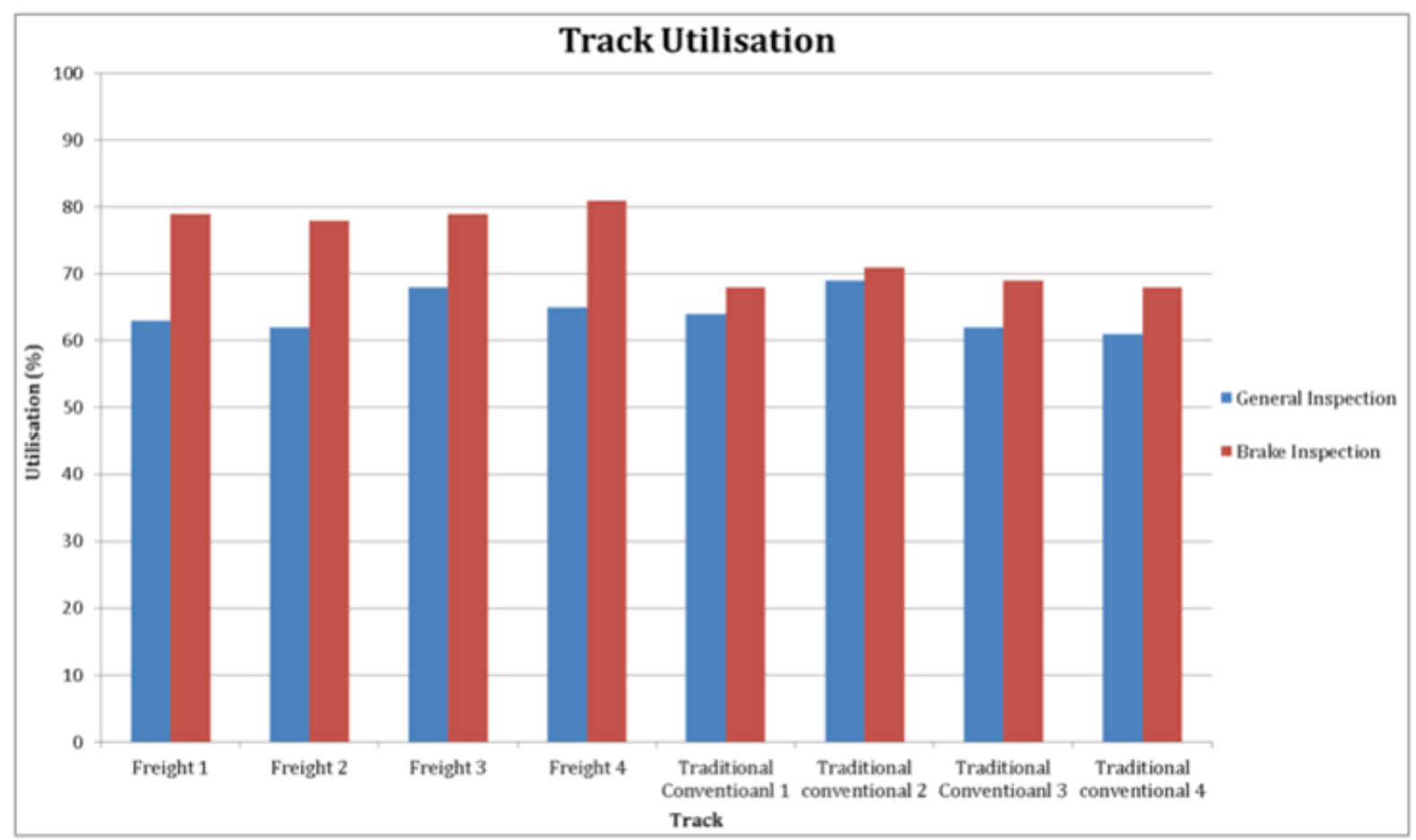

Figure 10 - Track utilisation graph for scenario one.

Based on the chosen quantities of tracks it is now possible to construct the layout of the yard by going backwards from the logic which resulted in the formulation of the initial simulation design. Figure 11 shows the final yard layout with the descriptive key in Table 7. Figure 11 has been designed using the described design method. The design provides the first step towards developing an interchange yard of the future which will allow for operating conventional rolling stock on high speed lines. 


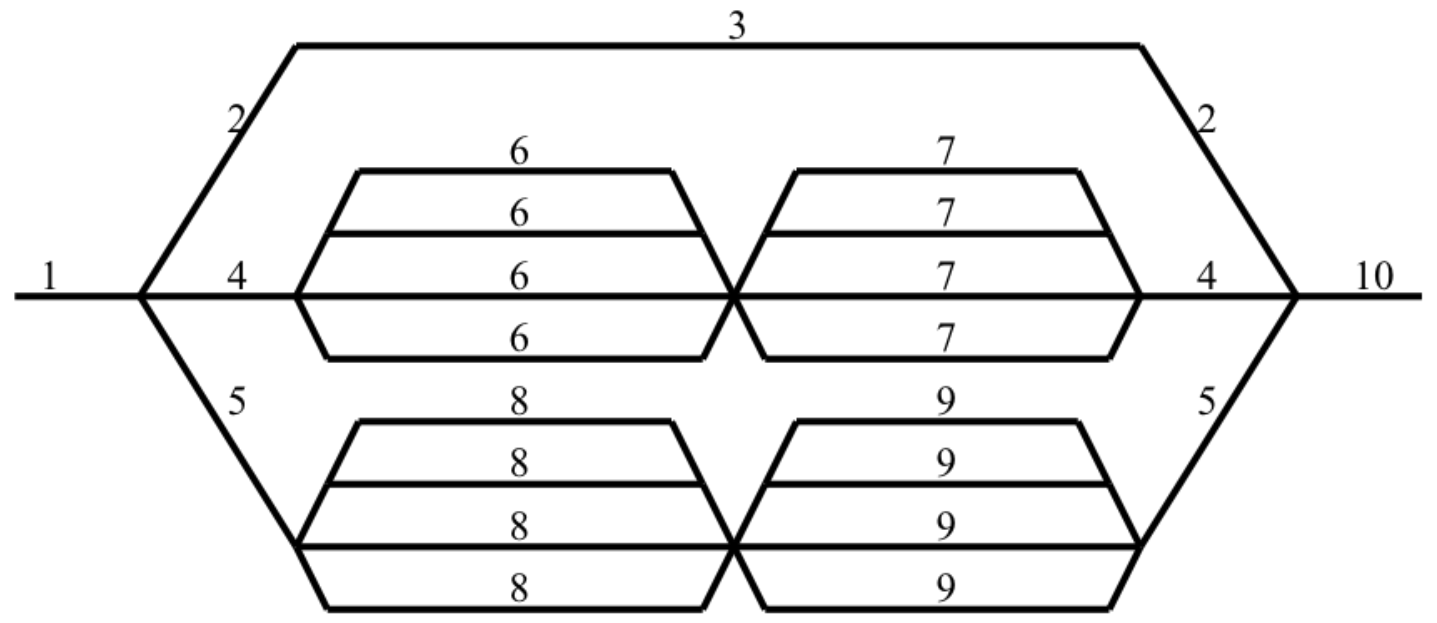

Figure 11 - Yard design between electrified high speed and electrified conventional lines.

\begin{tabular}{|l|l|l|l|}
\hline Number & Description & Number & Description \\
\hline 1 & Track to high speed line. & 6 & $\begin{array}{l}\text { General inspection station for traditional } \\
\text { conventional trains with buffer zone. }\end{array}$ \\
\hline 2 & Modern conventional track. & 7 & $\begin{array}{l}\text { Brake inspection station for traditional } \\
\text { conventional trains with buffer zone. }\end{array}$ \\
\hline 3 & $\begin{array}{l}\text { General inspection station for } \\
\text { modern conventional trains. }\end{array}$ & 8 & $\begin{array}{l}\text { General inspection station for freight } \\
\text { trains with buffer zone. }\end{array}$ \\
\hline 4 & Traditional conventional track. & 9 & $\begin{array}{l}\text { Brake inspection station for freight trains } \\
\text { with buffer zone. }\end{array}$ \\
\hline 5 & Freight track. & 10 & Track to electrified conventional line. \\
\hline
\end{tabular}

Table 7 - Yard design electrified high speed and electrified conventional lines key.

\subsection{Simulation Scenario Two - Electrified Track to Non-electrified Track}

\subsubsection{Scenario Two - Design}

The first step in designing the simulation for scenario two is similar to that for scenario one, whereby a process flow diagram must first be formulated. The difference with formulating a process flow diagram for scenario two is that it can be based upon the one which was produced for scenario one. However, as previously discussed, to allow a train with an electric locomotive to operate on a non-electrified track the locomotive must be changed to a diesel locomotive as the train is then capable of self-powering. Therefore, to facilitate a change of locomotive the process flow diagram from scenario one must be adapted to allow for the additional operation. A locomotive change must logically be carried out on a train before it goes through a general inspection or brake inspection as otherwise these two procedures must be carried out again afterwards, to ensure that the train is still in a suitable operating condition. Translating this to a simplified process diagram the procedure must then be arrival of train to the yard, trains which require a change of locomotive would then go through this operation, all trains would then go through a general inspection, a brake inspection and then finally they would depart the yard. Figure 12 shows the initial process flow diagram for scenario two.

However, due to rolling stock arriving from both the high speed and conventional lines the process flow diagram in Figure 12 does not necessarily account for this complexity. This complexity has been previously taken into consideration in the development of the simulation for scenario one, and subsequently the more complex diagram has been simplified accordingly. Therefore, it is possible 
to extend on the final scenario one process flow diagram by incorporating the logic of the process flow diagram in Figure 12, which adapts the diagram to be suitable for and applicable to scenario two.

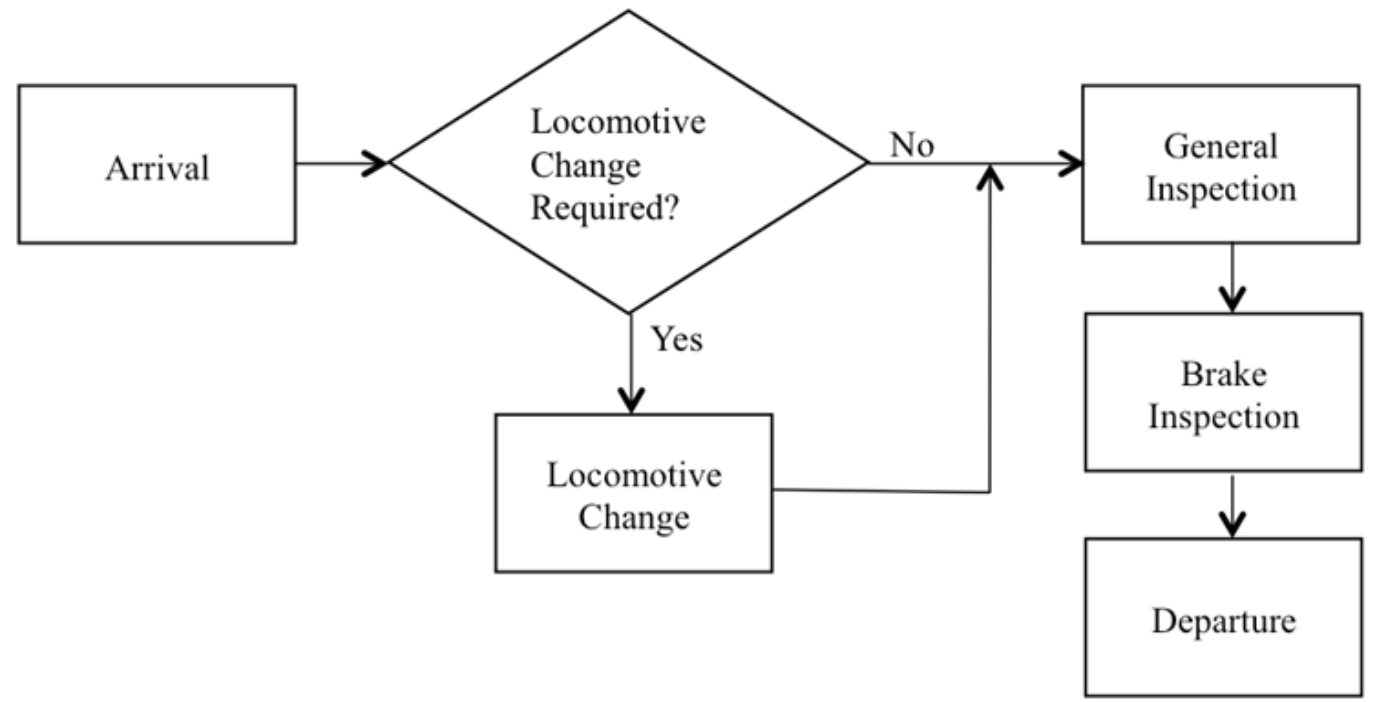

Figure 12 - Electrified high speed and non-electrified conventional process flow diagram.

Figure 13 gives the final process flow diagram for scenario two including both multidirectional travel and shared tracks.

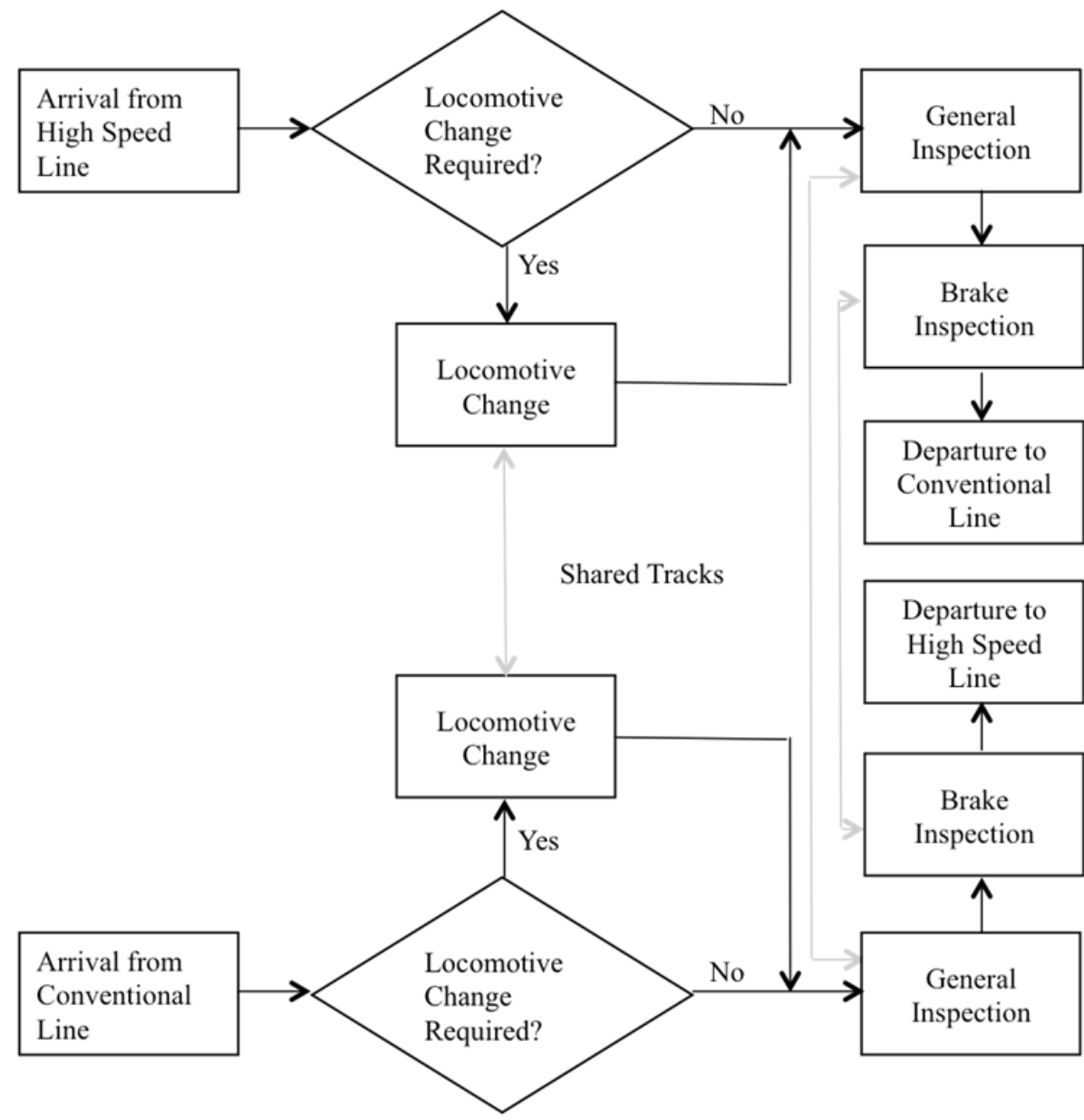

Figure 13 - Electrified high speed and non-electrified conventional process flow diagram with shared tracks. 
The process flow diagram can now be converted into an Arena diagram by utilising the modules which have been previously designed and combining them in the order shown in Figure 13. The results of this conversion can be seen in Figure 14, which is the final Arena simulation diagram for scenario two.

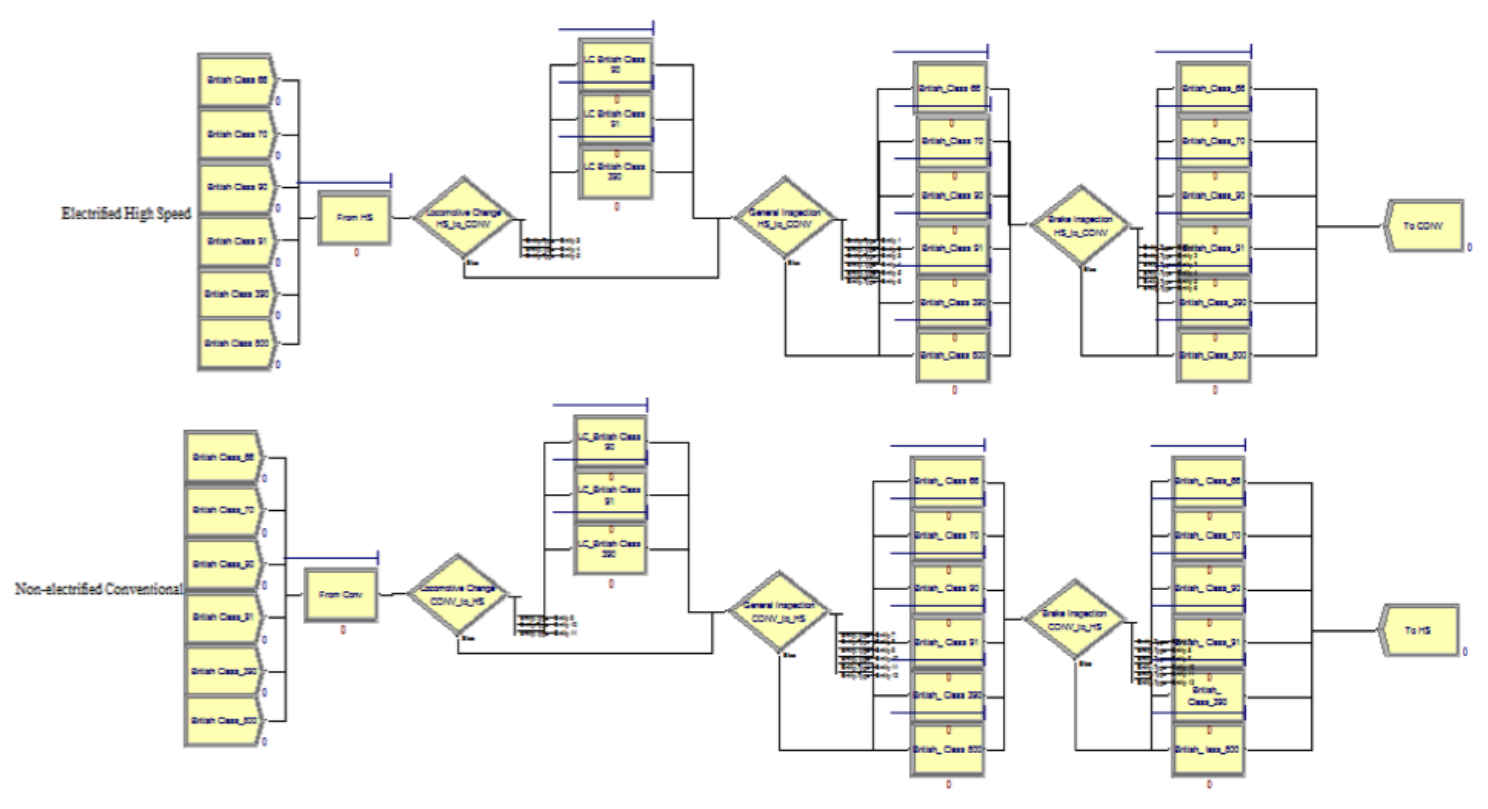

Figure 14 - Electrified high speed and non-electrified conventional Arena simulation model.

\subsubsection{Scenario Two - Method}

When applying a progressive design approach to scenario two a problem exists. The progressive approach such as that used in scenario one applies when there is only one variable, which in scenario one is the number of tracks which are input into the simulation. However, in scenario two, due to the extensive time taken for a locomotive to become available and then changed, a lot of tracks are utilised whilst queues build up. Therefore, a second variable exists here which is how many trains which require a locomotive change can arrive in a given period of time, which prevents the build up of excessive queues.

Based on scenario two having two variables the scenario will be broken down further into two different simulation situations which will give two different results. The first is to find the maximum arrival rate of rolling stock which requires a locomotive change for each quantity of track. To do this the quantity of tracks for the area where a locomotive is changed will start at one and be progressed up to six. The arrival rate of trains, which require their locomotive to be changed, will then be progressively increased for each quantity of track until a maximum arrival rate is found which prevents a build up in queue length.

The method for the second situation is to first choose the most realistic arrival rate of bi-mode rolling stock and rolling stock which requires a locomotive change as a reference. The next step is to increase the track quantities in the general inspection and brake inspection processes whilst the resultant queue times and utilisation of resources are recorded. From the resultant data it is then possible to find the track quantities which are the most effective. Based on the track quantities which are found a retrospective design method can then be used. 
However for these simulation methods to be carried out the first step, similar to scenario one, is to group types of rolling stock. By grouping different types of rolling stock by similarities it allows for a more applicable generalisation of the simulation to other types of rolling stock. As well as allowing for easier resource allocation in the simulation. The first grouping of the different types of rolling stock which are being discussed in this work is based on whether or not that type of rolling stock is bi-mode or whether it requires a locomotive change. Table 7 shows both of these groups with their respective trains.

\begin{tabular}{|l|l|}
\hline Group Name & Trains in Group \\
\hline Bi-mode & $\begin{array}{l}\text { British Class 66, British Class 70, } \\
\text { British Class 800 }\end{array}$ \\
\hline \multirow{2}{*}{ Requires Locomotive Change } & $\begin{array}{l}\text { British Class 90, British Class 91, } \\
\text { British Class 390. }\end{array}$ \\
\hline
\end{tabular}

Table 8 - Trains and the groups they will be classed by for the purposes of simulating scenario two based on whether or not a locomotive change is required.

The second group is based upon the classification of either freight, traditional conventional or modern conventional which was used in scenario one. However, the modern conventional train category has been reclassified to be modern bi-mode trains as other modern trains, such as the British Class 390, would require a brake inspection after a locomotive change which would otherwise be an unnecessary step. The updated groups can be seen in table 8 .

\begin{tabular}{|l|l|}
\hline Group Name & Trains in Group \\
\hline Freight & British Class 66, British Class 70 \\
\hline Other Conventional & British Class 90, British Class 91 \\
British Class 390 \\
\hline Modern Bi-mode & British Class 800 \\
\hline
\end{tabular}

Table 9 - Trains and the groups they will be classed by for the purposes of simulating scenario two.

\subsubsection{Scenario Two - Results}

The results for the maximum arrival rate of rolling stock which requires a locomotive change, without resulting in an increase in queue length, for track quantities between one and six for the locomotive change area of the yard can be seen in table 9 .

\begin{tabular}{|c|c|}
\hline Quantity of Tracks & Maximum Arrival Rate (Quantity/Hour) \\
\hline 1 & 2 \\
\hline 2 & 3 \\
\hline 3 & 7 \\
\hline 4 & 8 \\
\hline 5 & 10 \\
\hline 6 & 13 \\
\hline
\end{tabular}

Table 10 - Quantity of tracks and the respective maximum arrival rate (quantity/hour) of trains which require a locomotive change.

The results do have an approximately linear nature. The deviation from linearity is due to the inclusion of a probability distribution to allow for a more realistic representation of the emulated arrival system. However, these results do show the maximum capability of which the inclusion of each quantity of tracks would give the system. The quantity of tracks which is chosen for the first situation of this scenario is three tracks for the locomotive change process. The reason three tracks 
have been chosen is because it suggests a medium system capability towards allowing rolling stock which requires a locomotive change.

The simulated results for the second situation which allows for a solution to be found for the second variable for scenario two can be seen in table 10. A large number of simulations were run with a varied number of tracks and table 10 shows those which best represent the characteristics of each quantity of tracks.

\begin{tabular}{|c|c|c|c|c|c|c|}
\hline & & \multirow{4}{*}{$\begin{array}{l}\text { Group } \\
\text { Freight } \\
\text { Other Conventional } \\
\text { Modern Bi-mode }\end{array}$} & \multicolumn{4}{|c|}{ Quantity of Tracks } \\
\hline & & & 1 & 2 & 4 & 4 \\
\hline & & & 1 & 2 & 4 & 1 \\
\hline & & & 1 & 2 & 4 & 1 \\
\hline & & Train Class & Avera & Queue & es $(\mathrm{Mi}$ & \\
\hline \multirow{12}{*}{ 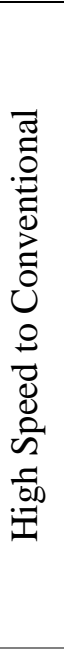 } & \multirow{6}{*}{ 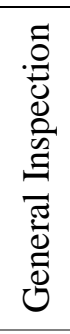 } & British Class 66 & 233.61 & 66.21 & 2.52 & 2.46 \\
\hline & & British Class 70 & 306.00 & 66.84 & 2.43 & 2.38 \\
\hline & & British Class 90 & 2.12 & 0.78 & 0.00 & 0.69 \\
\hline & & British Class 91 & 1.09 & 0.77 & 0.00 & 0.82 \\
\hline & & British Class 390 & 0.21 & 0.83 & 0.00 & 0.79 \\
\hline & & British Class 800 & 0.14 & 0.11 & 0.00 & 0.12 \\
\hline & \multirow{6}{*}{ 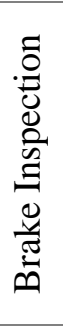 } & British Class 66 & 7.30 & 3.38 & 1.16 & 3.42 \\
\hline & & British Class 70 & 3.49 & 3.45 & 1.05 & 3.79 \\
\hline & & British Class 90 & 0.54 & 0.22 & 0.00 & 0.65 \\
\hline & & British Class 91 & 0.40 & 0.22 & 0.00 & 0.54 \\
\hline & & British Class 390 & 0.43 & 0.21 & 0.00 & 0.53 \\
\hline & & British Class 800 & 0.00 & 0.00 & 0.00 & 0.00 \\
\hline \multirow{12}{*}{ 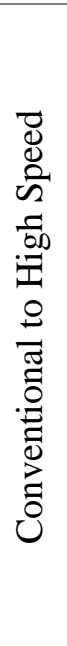 } & \multirow{6}{*}{ 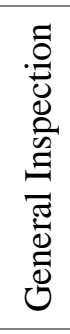 } & British Class 66 & 231.57 & 63.55 & 3.49 & 3.90 \\
\hline & & British Class 70 & 284.74 & 63.23 & 4.62 & 3.16 \\
\hline & & British Class 90 & 9.03 & 0.76 & 0.00 & 7.86 \\
\hline & & British Class 91 & 8.47 & 0.75 & 0.00 & 7.37 \\
\hline & & British Class 390 & 8.89 & 0.78 & 0.00 & 8.03 \\
\hline & & British Class 800 & 0.16 & 0.13 & 0.00 & 0.17 \\
\hline & \multirow{6}{*}{ 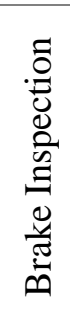 } & British Class 66 & 8.98 & 3.31 & 0.92 & 0.95 \\
\hline & & British Class 70 & 5.91 & 3.40 & 0.78 & 1.01 \\
\hline & & British Class 90 & 1.19 & 0.19 & 0.00 & 1.24 \\
\hline & & British Class 91 & 1.62 & 0.20 & 0.00 & 1.70 \\
\hline & & British Class 390 & 1.47 & 0.20 & 0.00 & 1.66 \\
\hline & & British Class 800 & 0.00 & 0.00 & 0.00 & 0.00 \\
\hline
\end{tabular}

Table 11 - Electrified high speed to non-electrified conventional queuing data.

By comparing the average queuing times of each train type with the utilisation of each track, the track quantities which are the most effective are four for freight, one for other conventional and one for modern bi-mode. This translates to one track for the general inspection of modern bi-mode trains, one track for the brake inspection and general inspection of other conventional trains and four brake inspection and general inspection tracks for freight trains. The queuing times for these quantities of track can be seen in Table 11 and the utilisation values can be seen in Figure 15 . However, similar to scenario one, the figures for the utilisation of the modern bi-mode tracks has been 
omitted as it cannot be calculated correctly by Arena due to the dynamic nature of the processing block.

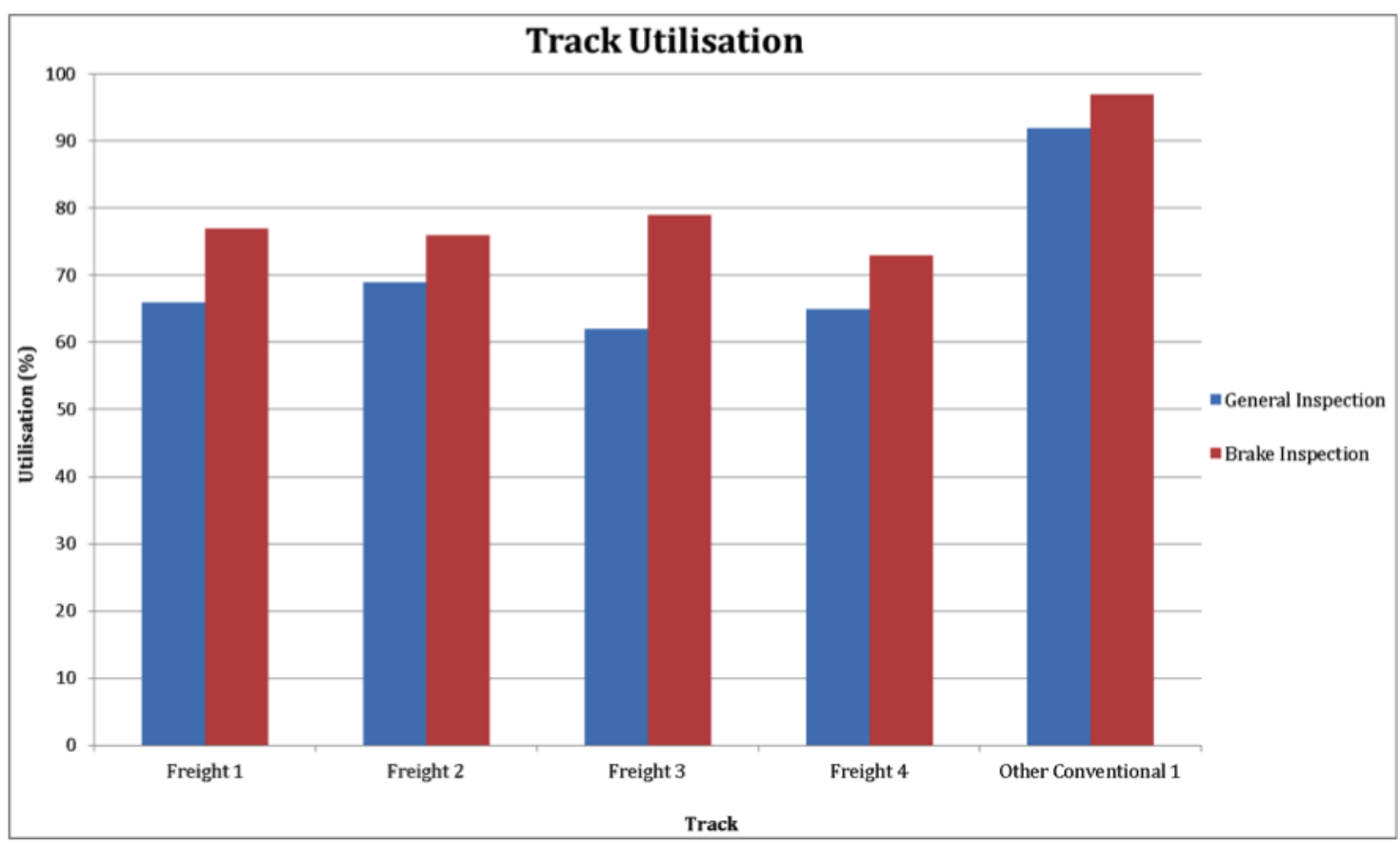

Figure 15 -Track utilisation graph for scenario two.

Utilising the same retrograde design method, which was explained and implemented in scenario one, the yard design in Figure 16 has been constructed with the explanatory key presented in Table 12.

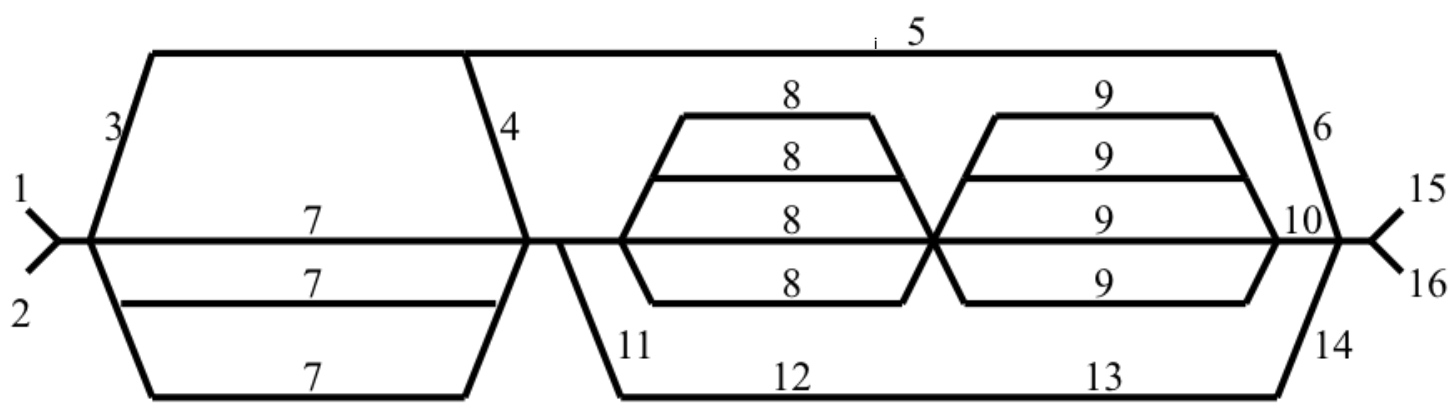

Figure 16 - Yard design between electrified high speed and non-electrified conventional. 


\begin{tabular}{|l|l|l|l|}
\hline Number & Description & Number & Description \\
\hline 1 & Track from high speed line. & 9 & $\begin{array}{l}\text { Freight train brake inspection station } \\
\text { and buffer zone. }\end{array}$ \\
\hline 2 & Track from conventional line. & 10 & Freight track out. \\
\hline 3 & $\begin{array}{l}\text { Bi-mode bypass of locomotive change } \\
\text { area. }\end{array}$ & 11 & $\begin{array}{l}\text { Other conventional train track to other } \\
\text { conventional inspection. }\end{array}$ \\
\hline 4 & $\begin{array}{l}\text { Bi-mode freight train track to freight } \\
\text { inspection. }\end{array}$ & 12 & $\begin{array}{l}\text { Other conventional train general } \\
\text { inspection station and buffer zone. }\end{array}$ \\
\hline 5 & $\begin{array}{l}\text { General inspection of modern bi-mode } \\
\text { trains. }\end{array}$ & 13 & $\begin{array}{l}\text { Other conventional train brake } \\
\text { inspection station and buffer zone. }\end{array}$ \\
\hline 6 & Modern bi-mode track out. & 14 & Other conventional track out. \\
\hline 7 & $\begin{array}{l}\text { Locomotive change station and buffer } \\
\text { zone. }\end{array}$ & 15 & Track to high speed line. \\
\hline 8 & $\begin{array}{l}\text { Freight train general inspection station } \\
\text { and buffer zone. }\end{array}$ & 16 & Track to conventional line. \\
\hline
\end{tabular}

Table 12- Yard design electrified high speed and non-electrified conventional key.

The design of the yard for scenario two is a more complex design than that which was designed for scenario one. A more complex design was required because scenario two requires both high speed and conventional lines to input from the same location. The reason for this is so that trains which require a locomotive change undergo this process prior to passing through the general inspection and brake inspection zones, as these process would have to otherwise be re-done after the locomotive was changed to ensure the train was still safe.

An additional feature of this design is that it contains a track which allows bi-mode trains to bypass the area where a locomotive is changed and then re-join the subsequent processing of the train in the correct zone. This eliminates the potential for bi-mode trains having to queue because of traffic in the area where a train's locomotive is changed.

The additional complexity and cost, which result from including an area where a locomotive can be changed, could be removed by stipulating that only bi-mode trains can pass through this type of interchange. In this case the yard design will be the same as that which was found for scenario one. Although, such a stipulation will not always be possible, which is why the interchange design for scenario two is still required.

Similar to scenario one, the design in Figure 16 provides the first step towards developing an interchange yard, which will allow for an interchange between a high speed railway and a conventional railway.

\section{Practical Implications}

The practical implications of this study come from the ability to interchange rolling stock between a high speed line and a conventional line. The benefit of being able to operate conventional trains on a high speed line with regard to the HS2 project is that it allows for the potential to delay the purchasing of high speed trains.

To be able to discuss delaying the purchasing strategy of high speed trains first it becomes necessary to look at the current purchasing plan. The current plans in the HS2 project specification are to buy both dedicated high speed trains and high speed trains which can be used on a conventional system termed classical compatible trains (HS2, 2009). Specific purchasing details have not yet been planned. However, without a specific plan it is still possible to discuss delaying the purchasing of high speed rolling stock. The reason it is still possible to discuss the purchasing of high speed rolling stock is that there are currently no plans to have any other trains running on the HS2 line so a logical 
assumption is that high speed rolling stock must be purchased to coincide with the opening of the line. By implementing the main concept of this work and delaying the purchasing it not only allows the capital outlay to be split over a longer time period which means that the investment represents a smaller percentile value of gross domestic product (GDP) each year but it also increases the utilisation potential of the current rolling stock.

One potential issue with running conventional trains on a high speed line, as discussed in section 2.3 , is that it reduces the capacity of the line by limiting the line speed as conventional trains can only achieve up to a maximum of $67 \%$ of that of high speed trains. The limitation on capacity which is imposed by conventional trains can however, be minimised by keeping the maximum speed of trains which operate on the line as high as possible. Consequently freight should not be operated at peak times as it is typically $46 \%$ slower than a passenger train at the moment however, this may change in the future. Maintaining a maximum top speed will also limit any potential customer dissatisfaction found from the journey time not being as short as it would be with a high speed train. Further to this, customer satisfaction could be found, as the HS2 line would reduce traffic on the current West Coast Mainline which would result in overall faster journey times. A further benefit is that by at first utilising conventional trains, when high speed trains are later introduced to the system the reduction in journey time that high speed trains offer would be more apparent to customers. Therefore, this would create customer satisfaction relative to the original condition.

The main challenges which are found in terms of cost and difficulty of implementation are based on the modification of a conventional train so that it can operate on a high speed line. There are two aspects of modifying a conventional train. The first aspect is the need to install ETRMS Level 2 onto the conventional trains which will run on the high speed network. In terms of difficulty of implementation and maintenance; introducing ERTMS Level 2 is minimal. However, a cost is associated with the purchasing and installation of the necessary equipment. A more significant challenge with the interoperability of conventional trains is the second aspect of modifying a train. The second aspect of modifying a conventional train is to inspect trains and change locomotives where necessary in train yards. This presents an issue to running conventional trains on a high speed line as it requires a yard to be built which will have a high capital cost. Furthermore, after the initial high capital cost a yard also has a running cost. However these costs are potentially not significant compared to the benefits produced from introducing an interchange. The benefits which are produced are a cost saving from delaying the purchase of high speed trains and the increased functionality of the rail network.

\section{Conclusion and Further Research}

\subsection{Conclusion}

This work presents two simulations and subsequently two interchange yard designs, which address the future need, of an interchange yard between a high speed railway and conventional railway. The first design which was presented was based on an interchange between an electrified high speed line and an electrified conventional line. The second design was an interchange between an electrified high speed line and a non-electrified conventional line.

The primary conclusion of this work is that it is possible to operate a conventional train on a high speed track through the use of an interchange yard. However, as a secondary conclusion, issues do occur due to operating conventional stock on a high speed line. Issues such as a reduced line capacity due to conventional rolling stock having a lower maximum top speed than high speed rolling stock. 
As an investigation into the potential of utilising conventional trains to alter the purchasing strategy of high speed rolling stock for the HS2 project to achieve a cost saving it becomes very successful. The key reason for this is that it not only shows that this is a possibility and indeed gives yard designs, but it also gives a simulation method which can be utilised at a later planning stage of the HS2 project to give a more accurate interchange design.

\subsection{Further Research}

Although this work does solve the initial question which was posed it could be extended further through additional work. Through the use of specific rail simulation software such as OpenTrack a more complex simulation model could be used and subsequently it may be able to relate to a more complex yard scenario.

Another example of this which would be a key area for further work is that a yard may be connected to both electrified and non-electrified conventional lines. This scenario is something which could not be simulated due to the complex nature of the scenario and the innate limitations of Arena.

An alternate area for further work would be to use the method which was extended upon in this work and apply it to a later planning stage of the HS2 project when more data is available. A more accurate simulation could then be utilised to allow for a new interchange yard design. Based on this newer design and the economic benefits which it would provide to the project for the reasons which have been previously discussed, the feasibility of the implementation of interchange yards could then be evaluated.

Further work could also be carried out on the location of the yard. Currently the exact route of the HS2 line has not been finalised. However, when the final route planning stage of the project has been passed a number of yard locations could be found through simulating the effect the interchange has on the surrounding conventional networks.

\section{References}

4Rail.net (2014) British Class 66. Available at: www.4rail.net/reference locoseur diesel c66.php (Accessed: 16/2/2014).

Alstom (2014) Very High Speed Train: AGV. Available at: www.alstom.com/transport/products-andservices/trains/very-high-speed-train-agv/ (Accessed: 23/2/2014).

Assad, A. (1980a) 'Modelling rail networks towards a routing/make-up model', Journal of Transportation Research, (14), p. 14.

Assad, A. (1980b) 'Models of Rail Transportation', Transportation Research Part A, 14, p. 15.

BBC (2013a) Spain Train Crash: What Happened. Available at: www.bbc.co.uk/news/world-europe23449336 (Accessed: 31/1/2014).

BBC (2013b) Spain Train Driver on Phone at Time of Deadly Crash. Available at: www.bbc.co.uk/news/world-europe-23507348 (Accessed: 31/1/14).

Boysen, N., Fliedner M., Jaehn F., Pesch E. (2012) 'Shunting Yard Operations: Theoretical Aspects and Applications', European Journal of Operational Research, 220(1), p. 14.

Cooper, R. (1981) Introduction to Queuing Theory. 2 edn. Florida Atlantic University: Elseveir North Holland Incorporated.

Department for Transport (2013) Rail Statistics. Available at: www.gov.uk/government/collections/rail-statistics (Accessed: 04/04/2014). 
Department of Transport (2012) 'Review of government stratergy for a national high speed rail network'.

European Council (2008) On The Interoperability Of The Railway System Within The Community. (Accessed: 28/3/2014).

European Railway Agency (2008) Technical Specification For Interoperability. (Accessed: 27/4/2014).

European Union (1996) European Directive 96/48/EC. (Accessed: 4/4/2014).

Flier, H. (2011) 'Optimisation of Railway Operations', Algorithms Complexity and Models.

Hitachi (2014a) The British Class 395. Available at: www.hitachirail-eu.com/class-395-highspeed 43.htlm (Accessed: 23/2/2014).

Hitachi (2014b) Hitachi Class 800. Available at: http://www.hitachirail-eu.com/hitachi-class-800series-train-selected-by-dft-_108.html (Accessed: 16/2/2014).

HS1 (2014) Who We Are. Available at: www.highspeed1.com/who-we-are (Accessed: 23/2/2014).

HS2 (2009) HS2 - High Speed Rail, London To The West Midlands And Beyond, HS2 Technical Appendix. (Accessed: 23/2/2014).

HS2 (2014a) HS2:Connectivity Journey Times. Available at: www.hs2.org.uk/about-hs2/factsfigures/connectivity-journey-times (Accessed: 31/1/2014).

HS2 (2014b) HS2:Economic Job Benefits. Available at: www.hs2.org.uk/what-hs2/economic-jobbenefits (Accessed: 31/1/2014).

HS2 (2014c) Phase One Map. Available at: www.hs2.org.uk/interactive-map (Accessed: 16/2/2014).

HS2 (2014d) Routes, Trains and Cost. Available at: www.hs2.org.uk/about-hs2/facts-figures/routestrains-cost (Accessed: 16/2/2014).

Kable (2007) Japanese Bullet Trains: 40 Years at the Forefront. Available at: www.railwaytechnology.com/features/feature1216 (Accessed: 9/2/2014).

Kable (2014a) British Class 390. Available at: www.railway-technology.com/projects/class390/ (Accessed: 16/2/2014).

Kable (2014b) ERTMS: European Rail Traffic Management System. Available at: www.railwaytechnology.com/projects/european-rail-traffic-management-system-ertms/ (Accessed: 5/4/2014).

Kable (2014c) HS1. Available at: www.railway-technology.com/projects/highspeedone/ (Accessed: 23/2/2014).

Kable (2014d) Pendolino Trains. Available at: www.railway-technology.com/projects/pendolino-train (Accessed: 16/2/2014).

Marinov M., and Viegas, J. (2009) 'A Simulation Modelling Methodology For Evaluating FlatShunted Yard Operations', Simulation Modelling Practice and Theory, 17(6), p. 23.

Marinov M., and Viegas, J. (2011) 'A Mesoscopic Simulation Modelling Methodology For Analysing and Evaluating Freight Train Operations in a Rail Network', Simulation Modelling Practice and Theory, 19(1), p. 23.

Network Rail (2010) Value and Importance of Freight. (Accessed: 23/2/2014).

Network Rail (2012a) European Freight Corridor Linking UK and Continental Europe. (Accessed: 23/2/2014).

Network Rail (2012b) Railway Topography. Available at: www.networkrail.co.uk/aspx/10563.aspx (Accessed: 16/2/2014).

Parker et al (2012) Design Considerations For Rail Maintanence Depots. Network Rail. 
Parsons Brinckerhoff (2011) 'High Speed Rail', Network, (73).

Peterman et al (2009) High speed rail in the united states. (Accessed: 23/2/2014).

Priemus et al (2004) 'Breakthrough Innovations In Intermodal Freight Transport', Transportation, p. 11.

Rail UK (2013) British Class 70. Available at: www.railuk.info/diesel/getclass.php?id=61 (Accessed: $16 / 2 / 2014)$.

Rail.co.uk (2013a) British Class 90. Available at: www.rail.co.uk/locomotives-and-engines/electricengines/british-rail-class-90/ (Accessed: 16/2/2014).

Rail.co.uk (2013b) British Class 91. Available at: www.rail.co.uk/locomotives-and-engines/electricengines/british-rail-class-90/ (Accessed: 16/2/2014).

Rail.co.uk (2013c) Locomotives and Engines. Available at: www.rail.co.uk/locomotives-and-engines/ (Accessed: 16/2/2014).

SDL (2014) ERTMS. Available at: www.railsigns.co.uk/info/ertms1/ertms1.html (Accessed: 5/4/2014).

Shalliker et al (1997) An Introduction to SIMUL8. University of Plymouth (Accessed: 7/4/2014).

The Rail Engineer (2013) New Eurostar Under Test. Available at: www.therailengineer.com/2013/10/31/new-eurostar-under-test (Accessed: 23/2/2014).

The Railway Centre (2013) British Class 373. Available at: www.therailwaycentre.com/Recognition\%20Tech\%20Data\%20EMU/EMU_373.html.

UIC (2013a) General Definition Of High Speed. Available at: www.uic.org/spip.php?article971 (Accessed: 9/2/2014).

Williams, M. (2011) 'Using Simulation To Understand Bottlenecks, Delay Accumulation and Rail Network Flow', American Railway Engineering and Maintanence-of-way Association.

Xuemei et al (2008) Research on the development of railway industry in China and the corerlation between railway and natioanl economy based on input-output analysis. Beijing Jiaotong University (Accessed: 10/4/2014).

Zhou et al (2008) 'Simulation Research About the Number of Lines in a Passanger Rolling Stock Servicing Yard on Arena', Plan, Build and Manage Transportation in China. 